\title{
DEVELOPMENT OF A PHENOMENA IDENTIFICATION AND RANKING TABLE FOR THERMAL-HYDRAULIC PHENOMENA DURING A DOUBLE-ENDED GUILLOTINE BREAK LOCA IN AN SRS PRODUCTION REACTOR
}

\author{
R. G. Hanson \\ M. G. Ortiz \\ M. A. Bolander \\ G. E. Wilson
}

July 1989

EG\&G Idahn, Inc.

Idaho Falls, Idaho 83415

Prepared for the U.S. Department of Energy

Idaho Operations Office

Under DOE Contract No. DE-AC07-76ID01570

CUSTRADTHOA OF THHS DOCUMENT IS UMLIMHEO 


\begin{abstract}
A rising level of scrutiny is being directed toward the Savannah River Site (SRS) production reactors. Improved calculational capabilities are being developed to provide a best estimate analytical process to determine the safe operating margins of the reactors. The Code Scaling, Applicability, and Uncertainty (CSAU) methodology, developed by the U. S. Nuclear Regulatory Commission to support best estimate simulations, is being applied to the best estimate limits analysis for the SRS production reactc s. One of the foundational parts of the method is the identification and ranking of all the processes that occur during the specific limiting scenario. The phenomena ranking is done according to their importance to safety criteria during the transient and is used to focus the uncertainty analysis on a sufficient, yet cost effective scope of work. This report documents the thermal-hydraulic phenomena that occur during a limiting break in an SRS production reactor and their importance to the uncertainty in simulations of the reactor behavior.
\end{abstract}




\section{SUMMARY}

The increased scrutiny directed toward the operation of Department of Energy production reactors in recent years has led to the development and incorporation of best-estimate computer codes in the safety analysis process. The use of best-estimate techniques requires that the analysis be accompanied by a quantification of the uncertainty in the calculated results. The operating power limit for the SRS production reactors is determined through the use of computer codes. The CSAU methodology, developed by the U. S. Nuclear Regulatory Commission to support best estimate analyses for light water reactors, is being applied to the power limiting transient for the SRS production reactors.

The first segment in the CSAU methodology is the identification and ranking of phenomena that are important to the limiting scenario. Since it is not cost effective to assess all models in the code the CSAU method provides justification for investigating only the important phenomena. The selection is made according to a ranking of the importance the phenomena have with respect to safe reactor operations. The purpose of this report is to identify the thermal-hydraulic phenomena associated with the limiting break in an SRS production reactor and their importance to the safety criteria used to establish acceptable safety margins.

Three relatively independent panels of reviewers performed the identification and subsequent ranking of phenomena for an SRS production reactor. The first effort of ranking the phenomena was performed at the Idaho National Engineering Laboratory (INEL) by personnel familiar with safety analysis of commercial power and production reactors. The serond effort to rank the phenomena was perforned by a Technical Program Group (TPG), representing experts from academia, industry, and the national labs. The third effort was performed by a group made up of experts from the Savannah River Laboratory (SRL). The TPG reviewed the results of each of the panels and arrived at an integrated, and sufficiently complete Phenomena Identification and Ranking Table (PIRT). 


\section{ACKNOWLEDGMENTS}

The authors wish to thank and acknowledge the following people for their contributions to this document: Members of the SRL TPG for their review and comment of this document and E. Jenkins and C. McKenzie for their support in preparing the document graphics. 


\section{CONTENTS}

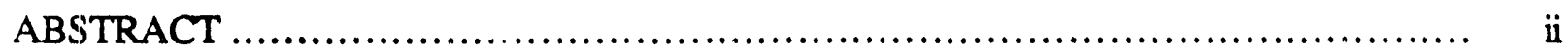

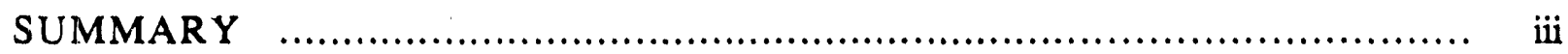

ACKNOWLEDGMENTS ........................................................... iv

1. INTRODUCTION …............................................................ 1

2. LIMITING TRANSIENT SCENARIO DESCRIPTION .............................. 2

2.1 Overview of the Limiting Transient Scenario ............................. 2

2.2 Initial and Transient Initiation Conditions ............................... 4

$2.3 \quad$ FI Phase Scenari ......................................................... 6

$2.4 \quad$ ECS Phase Scenario .................................................. 11

3. PHENOMENA IDENTIFICATION AND RANKING METHODOLOGY ......... 19

3.1 Component Identification ....................................... 19

3.2 Phenomena Identification ........................................ 26

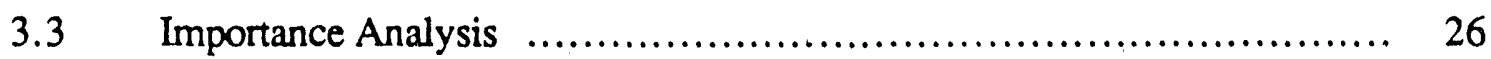

Effect of Proposed System Modifications to
the PIRT Process

4. RESULTS OF THE PHENOMENA IDENTIFICATION AND RANKING ........ 28

4.1 PIRT Results for the Independent Evaluations ........................ 28

$4.2 \quad$ Integrated PIRT Results .......................................... 33

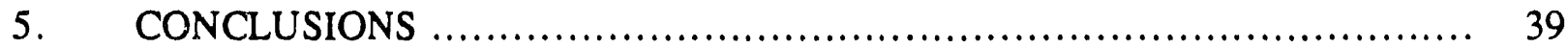

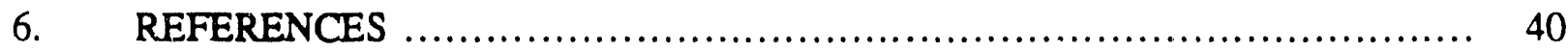

APPENDIX A-INDEPENDENT PANELS USED FOP. THE IDENTIFICATION

AND RANKING OF PHENOMENA FOK DEGB LOCA ................ A-1

APPENDIX B--INDIVIDUAL PHENOMENON DESCRIPTION ......................... B-1

APPENDIX C--COMPONENT RANKINGS

APPENDIX D--ANAL,YTICAL HIERARCHICAL PROCESS ............................... D-1

APPENDIX E--COMPARISON AND RESOLUTION OF RANKINGS .................. E-1 


\section{FIGURES}

1. Sketch of $L$-Reactor indicating operating flow magnitudes and directions, as well as the assumed location of the DEGB

(right hand loop) and the location of the ECS injection ports

2. (a) Break flow, (b) tank liquid level, (c) ECS flow, and (d) normalized break flow, tank level, and ECS flow versus time of the limiting break transient indicating relative occurrence of FI and ECS phases

3. Sketch of the reactor at break initiation, indicating

flows, levels, and pressures

4. Normalized reactor power for the first $10 \mathrm{~s}$ indicating

the FI phase

5. Sketch of the reactor $1 \mathrm{~s}$ after break initiation indicating flows, levels, and pressures

6. Pressure drop across the reactor from plenum to bottom of the tank: (a) for the first $2 \mathrm{~s}$, and

(b) throughout the entire simulation

7. FI occurrence showing the uneven distribution of pressure and flow caused by (a) the break, (b) boiling in a channel with insufficient coolant flow, and (c) boiling propagating throughout the entire channel

8. Sketch of the reactor $12 \mathrm{~s}$ after break initiation showing the pumps beginning to aspirate air into the loops

9. Liquid fraction response for the (a) broken and

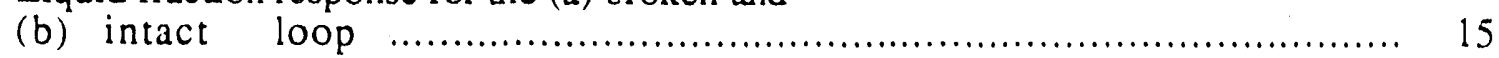

10. Sketch of the reactor $25 \mathrm{~s}$ after break initiation ......................................... 16

11. Sketch of the reactor $50 \mathrm{~s}$ after break initiation ............................................ 16

12. Sketch of the reactor $100 \mathrm{~s}$ after break initiation ....................................... 16

13. Sketch of the reactor $200 \mathrm{~s}$ after break initiation ....................................... 17

14. Heat removal rate from the fuel assembly as a function of time ......................... 18

\section{TABLES}

1. Component and phenomena hierarchy for the DEGB for the FI phase as identified by the INEL panel 
2. Component and phenomena hierarchy for the DEGB for the

ECS phase as identified by the INEL panel

3. Component and phenomena hierarchy for the DEGB for the FI phase as identified by the TPG experts panel

4. Component and phenomena hierarchy for the DEGB for the

ECS phase as identified by the TPG experts panel

5. Component and phenomena hierarchy for the DEGB for the

FI phase as identified by the SRL panel

6. Component and phenomena hierarchy for the DEGB for the

ECS phase as identified by the SRL panel

7. Comparison of the independent importance ranking results

for the FI phase of a DEGB in an SRS production reactor

8. Comparison of the independent importance ranking results

for the ECS phase of a DEGB in an SRS production reactor

9. Composite PIRT for the FI phase of the limiting DEGB LOCA

for an SRS production reactor

10. Composite PIRT for the ECS phase of the limiting DEGB LOCA

for an SRS production reactor

A-1. Panel Members

C-1. Component ranking for the FI phase of a limiting LOCA

C.2

C-2. Component ranking for the ECS phase of a limiting LOCA

E-1. Comparison and resolution of rankings in the FI phase

E-2. Comparison and resolution of rankings in the ECS phase 


\section{DEVELOPMENT OF A PHENOMENA IDENTIFICATION AND RANKING TABLE FOR THERMAL-HYDRAULIC PHENOMENA DURING A DOUBLE-ENDED GUILLOTINE BREAK LOCA IN AN SRS PRODUCTION REACTOR}

\section{INTRODUCTION}

Thermal-hydraulic computer codes have become the primary analysis tools used to determine safe operating limits for both commercial and production reactors. Consequently, it has become necessary to quantify the uncertainty associated with the calculated operating limits and consider that uncertainty in establishing safe operating margins. A method for uncertainty quantification has been developed by the U. S. Nuclear Regulatory Commission for use in the commercial reactor community. The Code Scaling, Applicability, and Uncertainty (CSAU) methodology ${ }^{1}$ is generic at the process level, but specific in application to a selected code, transient type, and plant configuration. The method is currently being applied to the Savannah River Site (SRS) production reactors for the limiting transient.

This report documents the first segment of the CSAU application to the SRS production reactors. This segment, the development of a phenomena identification and ranking table (PIRT), consists of identifying the limiting transient and unique phases of the transient, identifying all components active during each accident phase, identification of all phenomena occurring during the transient phase that will affect the safety criterion, and ranking of the phenomena importance to the uncertainty in determining safe operating margins. The identified important phenomena will be used to evaluate the applicability of thermal-hydraulic computer codes to the specific problem. The identified important phenomena will also focus the quantification of code uncertainty into a sufficient and efficient evaluation of safety margins.

The following sections present a description of the limiting transient for the SRS production reactors, a description of the PIRT process, and the results of three independent PIRT evaluations and their integration into an accurate and complete picture of the phenomena important to uncertainty quantification. Conclusions are then presented. 


\section{LIMITING TRANSIENT SCENARIO DESCRIPTION}

The operating power and effluent temperature limits ${ }^{2}$ for the SRS production reactors are established using a suite of computer codes to calculate reactor response to a number of accident scenarios. At present, the limiting transient scenario is a double-ended guillotine break loss-ofcoolant accident (DEGB LOCA). This section presents a description of the limiting transient scenario in the SRS production reactors.

The SRS production reactors are identical in configuration with few minor differences. The reactors behave the same during normal operation and the same phenomena is expected during a DEGB LOCA. Figure 1 presents a schematic of an SRS production reactor and loop piping. The system includes six coolant loops which are similar. Figure 1 shows a two-loop representation of the system in which five intact loops are lumped together and the broken loop is shown separately with a break represented at the plenum inlet. Four of the six coolant loops include connection to the Emergency Cooling System (ECS). The primary flow path is as follows. Coolant is pumped from the moderator tank to two parallel heat exchangers in each loop. The coolant flows through the heat exchangers and is discharged into the water plenum. The coolant passes through the slotted sleeves and enters the top of the fuel assemblies. The coolant exits near the bottom of the fuel assemblies and enters the moderator tank. The gas plenum and the blanket gas system serve to maintain the normal system operating pressure. The arrows in Figure 1 indicate the nominal flow direction throughout the system. A minor flow path on the primary side takes coolant from the heat exchangers and injects it from the bottom of the tank up into the $\operatorname{sep}^{*}$. oils.

The following sections provide an overview of the limiting transient scenario, a brief description of the initial conditions prior to the DEGB LOCA, and a presentation of the phenomena occurring during the transient.

\subsection{OVERVIEW OF THE LIMITING TRANSIENT SCENARIO}

There are two stages of interest in a DEGB LOCA in the production reactor. The first, the flow instability (FI) phase, spans the time from break initiation to the start of ECS injection. During this phase, the heat flux released from the core may exceed the ability of the primary cooling system to remove it without bringing about the production of significant voiding due to subcooied nucleate boiling. The second stage, the ECS phase, begins when ECS flow is delivered to the reactor loops. At the beginning of the ECS phase, the reactor power is limited to decay heat, 


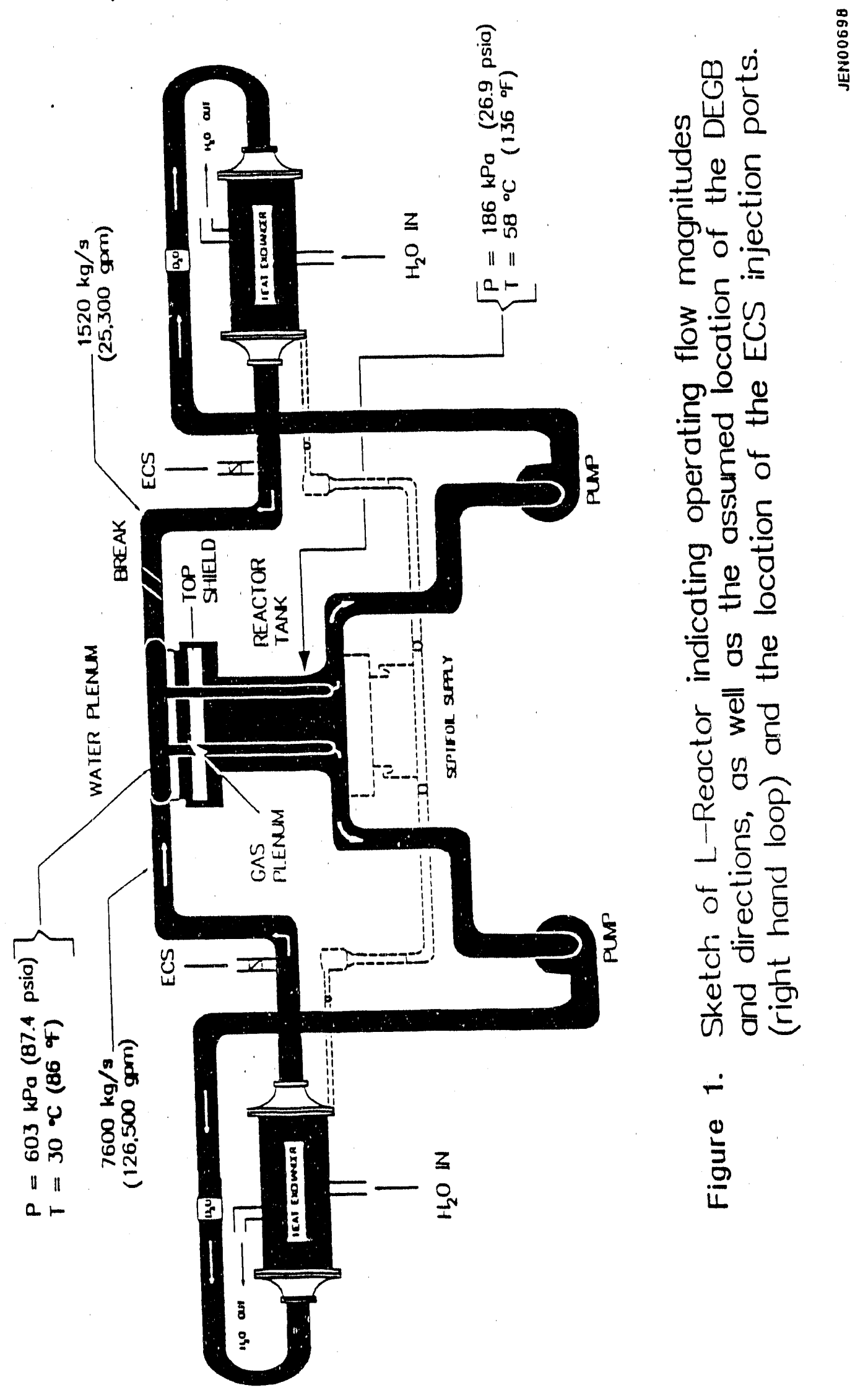


but a significant amount of coolant inventory will have been lost. The ECS adds inventory (light water ) to the existing inventory (heavy water), both of which are pumped to the water plenum. The total coolant available is expected to be sufficient to remove the decay heat if the distribution of coolant amongst the fuel assemblies is adequate. The distribution depends on the break flow, tank level, ECS flowrate, and the void fraction in the plenum.

An overview of a DEGB LOCA, based on a scoping calculation ${ }^{3}$, is presented in Figures $2 \mathrm{a}$ through $2 \mathrm{~d}$. Figure $2 \mathrm{a}$ is a plot of the break flow that initiates and subsequently dominates the transient. Figure $2 \mathrm{~b}$ is a plot of the moderator tank liquid level that drops as a consequence of the loss of coolant through the break. Figure $2 \mathrm{c}$ shows the ECS flow activated by the low level in the moderator tank. Figure $2 d$ provides a normalized representation of the three variables showing their relative behavior during the first $20 \mathrm{~s}$ of the transient. Following the FI phase, the ECS is activated when the tank levels reaches $3.3 \mathrm{~m}(10.8 \mathrm{ft})$, at about $6.5 \mathrm{~s}$. The ECS flow reaches a maximum and steady level at approximately $16.5 \mathrm{~s}$. The liquid level appears to be slowly approaching a stable state by $200 \mathrm{~s}$.

\subsection{INITIAL AND TRANSIENT INITIATION CONDITIONS}

It is assumed the moderator tank, water plenum, and fuel assemblies are operating in a steady state, liquid full condition prior to the DEGB LOCA. Approximately $1.525 \mathrm{~kg} / \mathrm{s}$ (3362 lbm/s or $24,200 \mathrm{gpm}$ ) of coolant is flowing through each of the six loops $(9,150 \mathrm{~kg} / \mathrm{s}$ [20172 lbm/s or $145,200 \mathrm{gpm}$ ] total): The moderator tank level is maintained at $5.8 \mathrm{~m}(19 \mathrm{ft})$ by means of an overflow weir and makeup system in the blanket gas space above the top shield. The water temperature in the plenum is $30^{\circ} \mathrm{C}\left(86^{\circ} \mathrm{F}\right)$, and it increases through the reactor to $58^{\circ} \mathrm{C}$ $(136$ of) at the exit nozzles.

The transient presented herein is assumed to be initiated by a double-ended guillotine break in one of the plenum inlet lines. It should be noted that the plenum inlet break may not be the worst location for the limiting transient. For example, a plenum inlet break is likely to be the worst location for the FI phase. However, another break location is likely to give more severe conciitions for ECS limits. The break location for the limiting transient is to be identified during the analysis. The plenum inlet piping was selected for the break location in this transient description because it shows both the FI and the ECS phases.

The initial break flow rate is defined to be equal to the initial loop flow $(1,525 \mathrm{~kg} / \mathrm{s}$ [ $3362 \mathrm{lbm} / \mathrm{s}$ or $24,200 \mathrm{gpm}$ ]) because the break is assumed to be instantaneous. After the break 

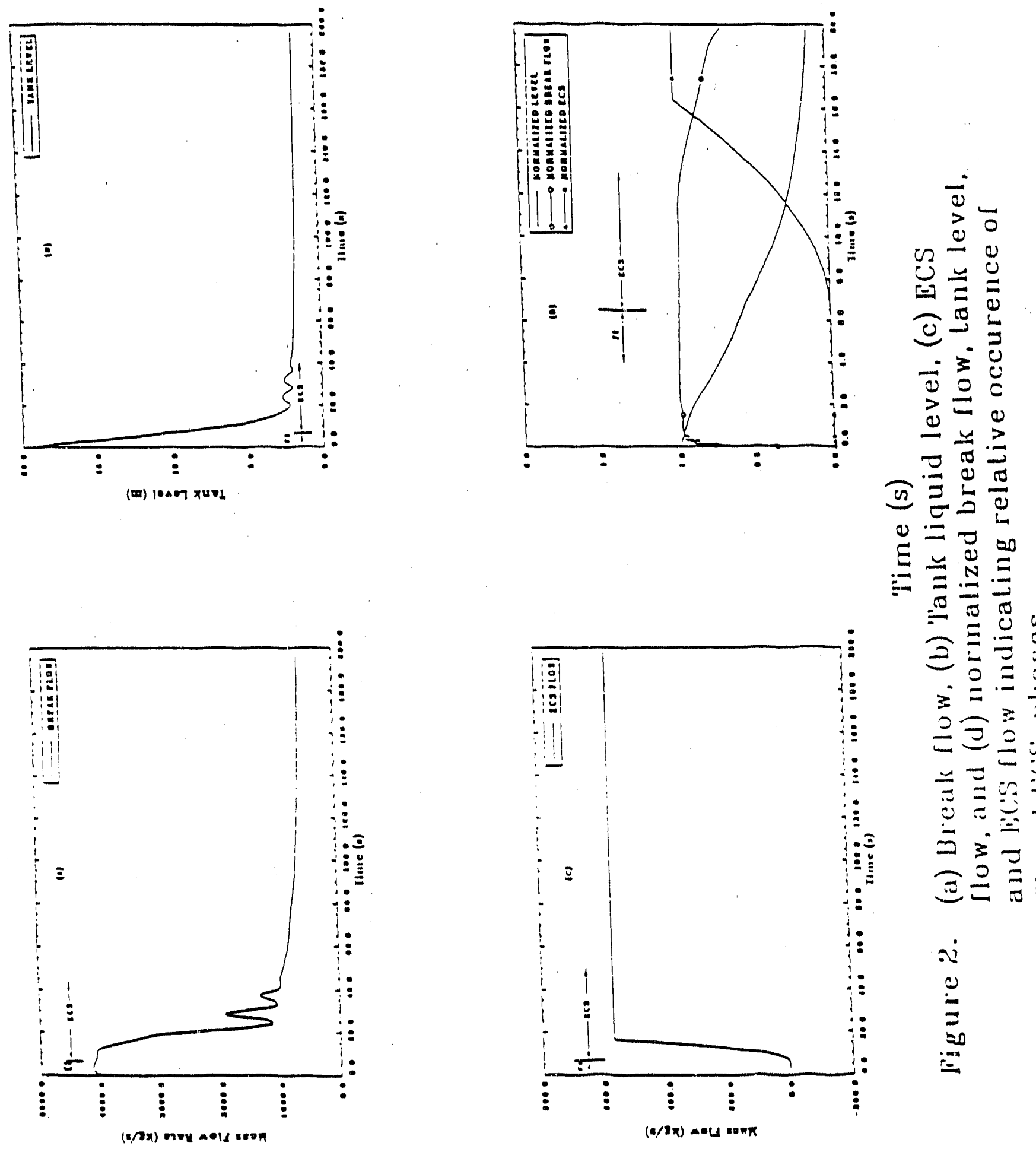

$\Rightarrow \equiv 0$

$2 \equiv=0$

-2 $=0$

$\geq \equiv-1=$

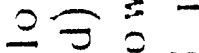

$- \pm \equiv$

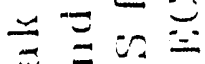

$\Xi \approx=$

$23=\equiv$

을

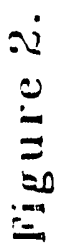


occurs, the total break flow increases rapidly as the flow on the plenum side of the break reverses. Figure 3 illustrates the system thermal-hydraulic conditions at the instant of the break.

\subsection{Fi Phase Scenario}

The next iwo sections present the phenomena occurring in the system during the DEGB LOCA. Section 2.3 presents the phenomena occurring during the FI phase of the scenario, and Section 2.4 presents the phenomena occurring during the ECS phase of the scenario.

Immediately after the break occurs, the total break flow increases rapidly primarily due to the fluid escaping the plenum through the break. The plenum depressurizes rapidly, which is immediately detected by the control rod shutdown system. It is estinated that 0.3 - is required by the system to process the signal and trigger the reactor trip, with an additional $0.7 \mathrm{~s}$ lapse before the safety rods begin entering the reactor. Thus, there is an effective reacter trip delay of about $1 \mathrm{~s}$. Figure 4 shows the core power history during the first few seconds of the transient scenario. The reactor power remains constant for the first $0.7 \mathrm{~s}$, while coolant flow and pressure drop sharply. Figure 5 illustrates the conditions at one second indicating a small, but perceptible drop in the liquid level of the gas plenum, accompanied by significant changes in break flow and plenum pressure.

The break produces several immediate interdependent effects which are summarized below:

1 The totai break flow rapidly increases initially, beyond the pre-break loop flow as shown in Figures $2 \mathrm{a}$ and $2 \mathrm{~d}$. Note that in this scenario, the break flow comes from both the heat exchanger side and the water plenum side.

2 The water path through the reactor competes with the break for a continually decreasing head in the plenum. Thus, the water flow through the reactor decreases initially, until a quasi-equilibrium condition is achieved during the FI phase. Figure 6 shows the pressure drop across the reactor between the plenum and the bottom of the reactor tank. In less than $0.5 \mathrm{~s}$ the pressure drop through the core approaches a stable value of about $50 \%$ of its initial value.

3 The large reduction in reactor pressure and assembly flow may create conditions conducive wo subcooled nucleate boiling in the assemblies and potential flashing in the 


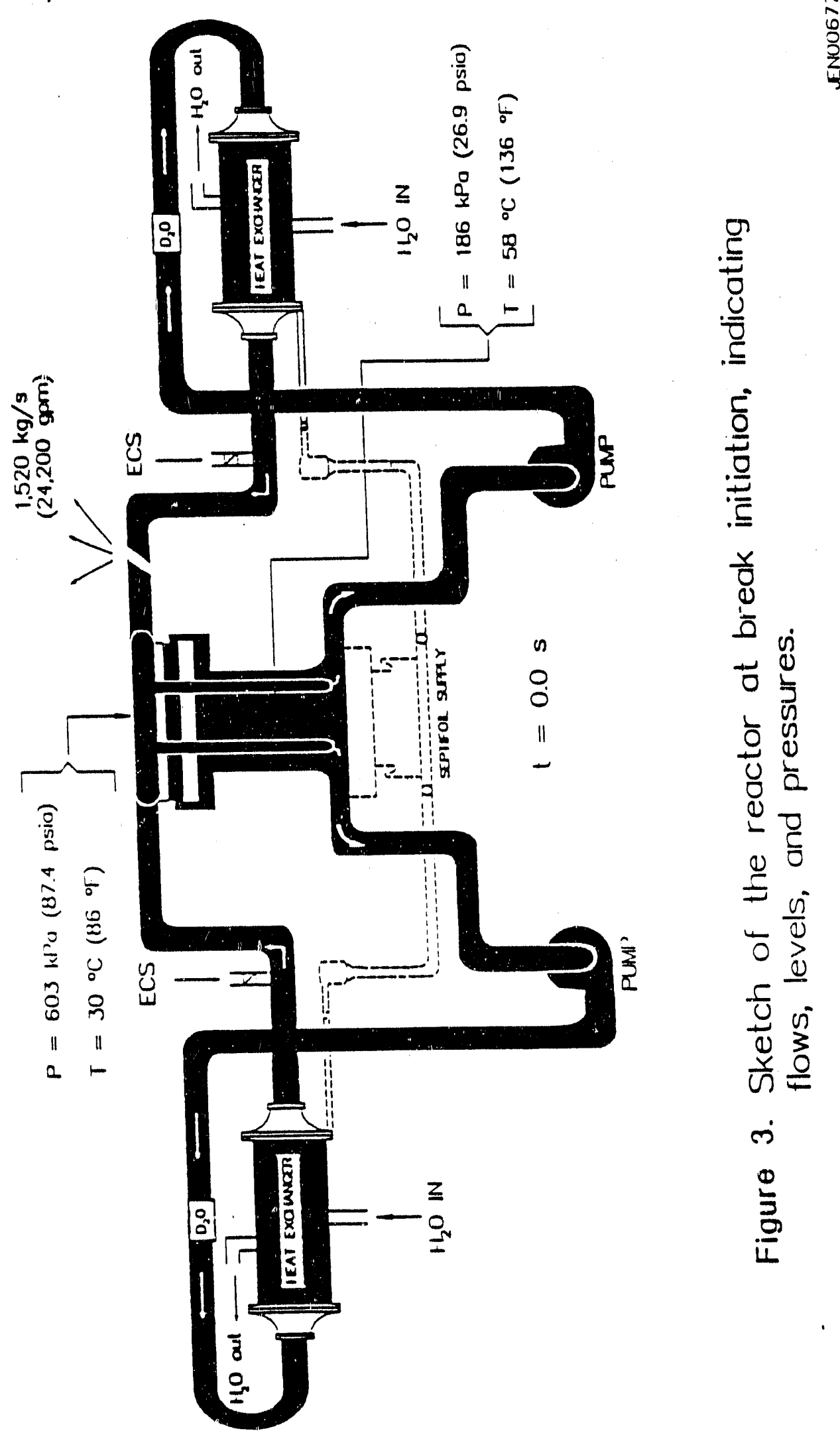




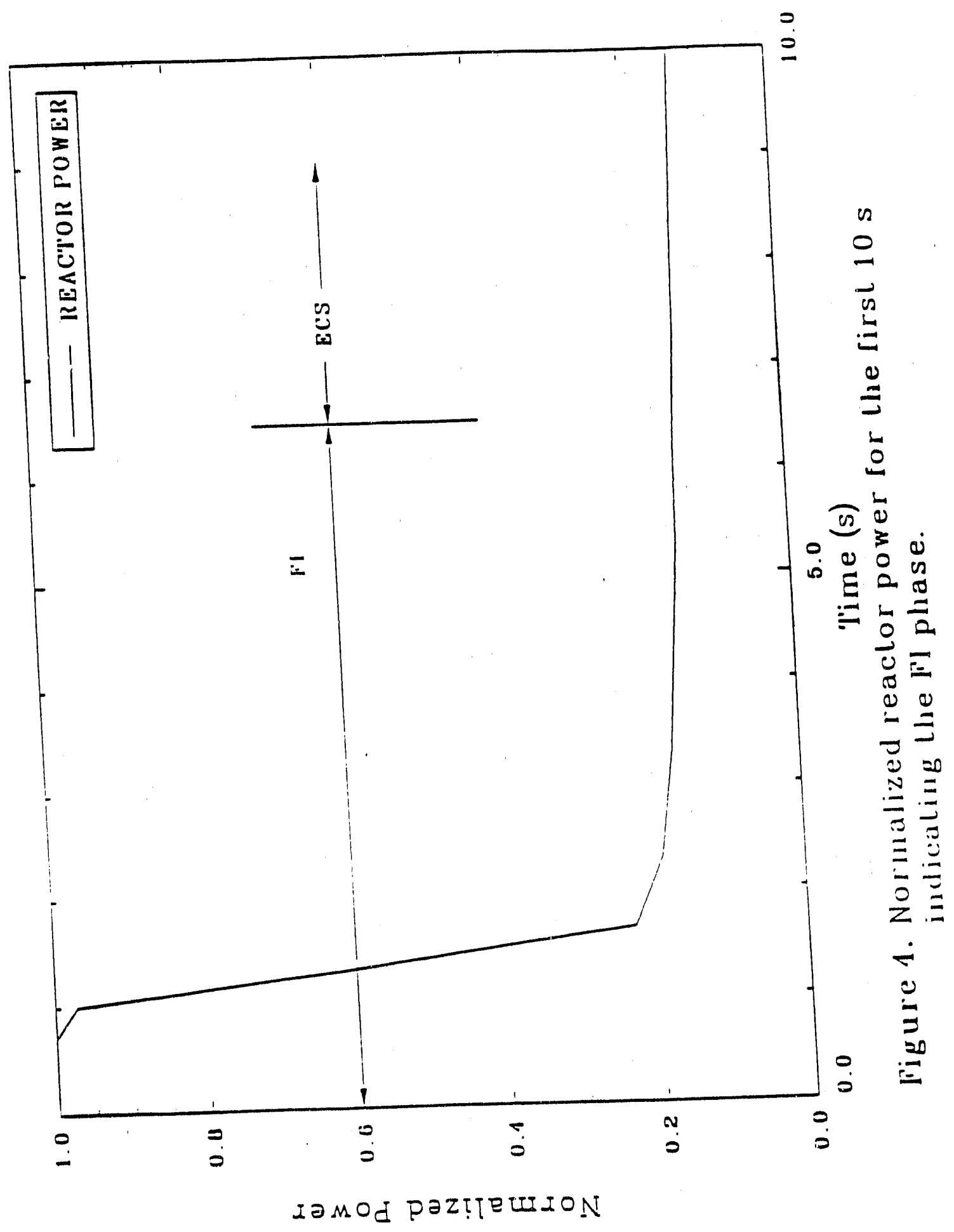




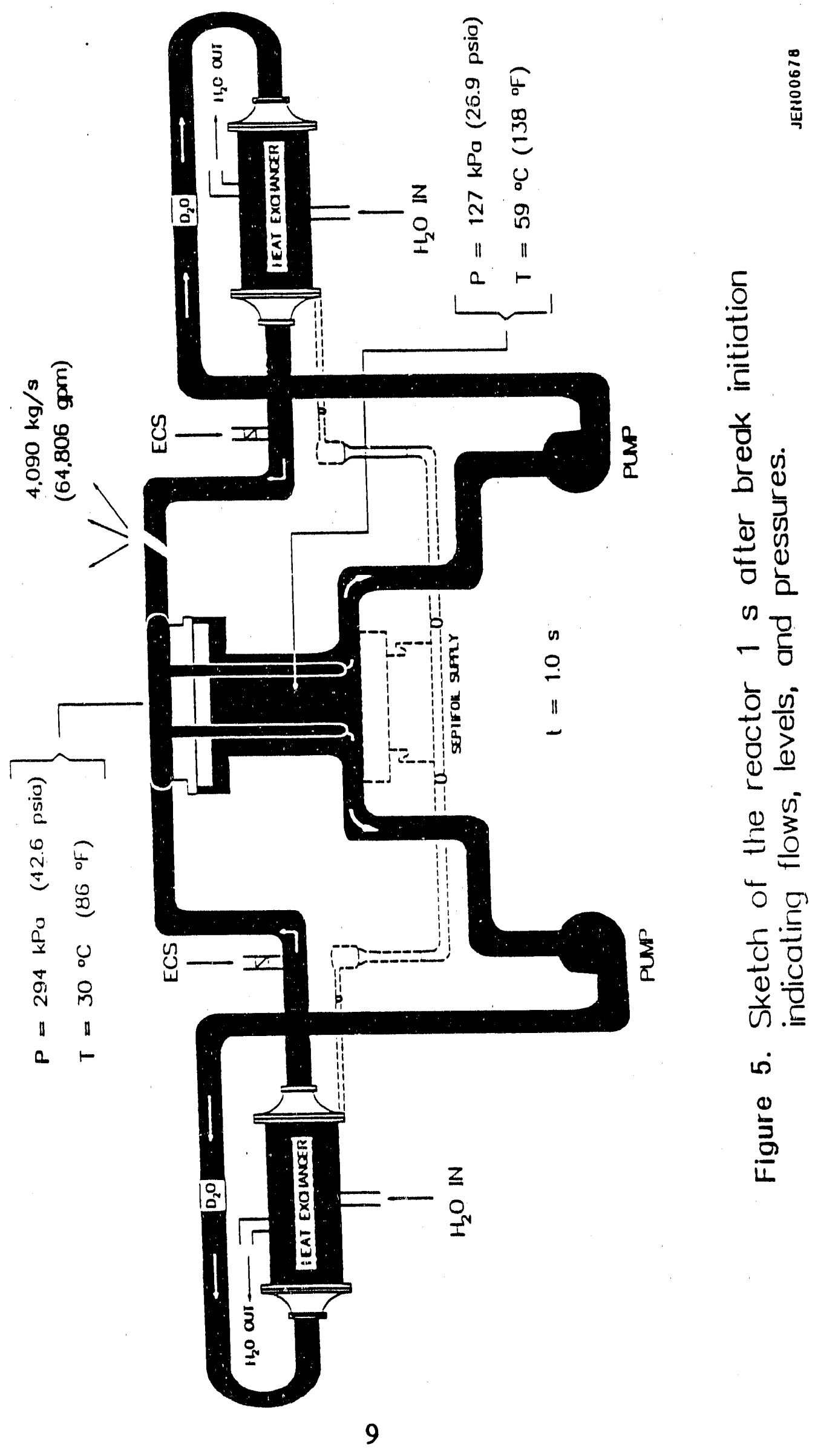



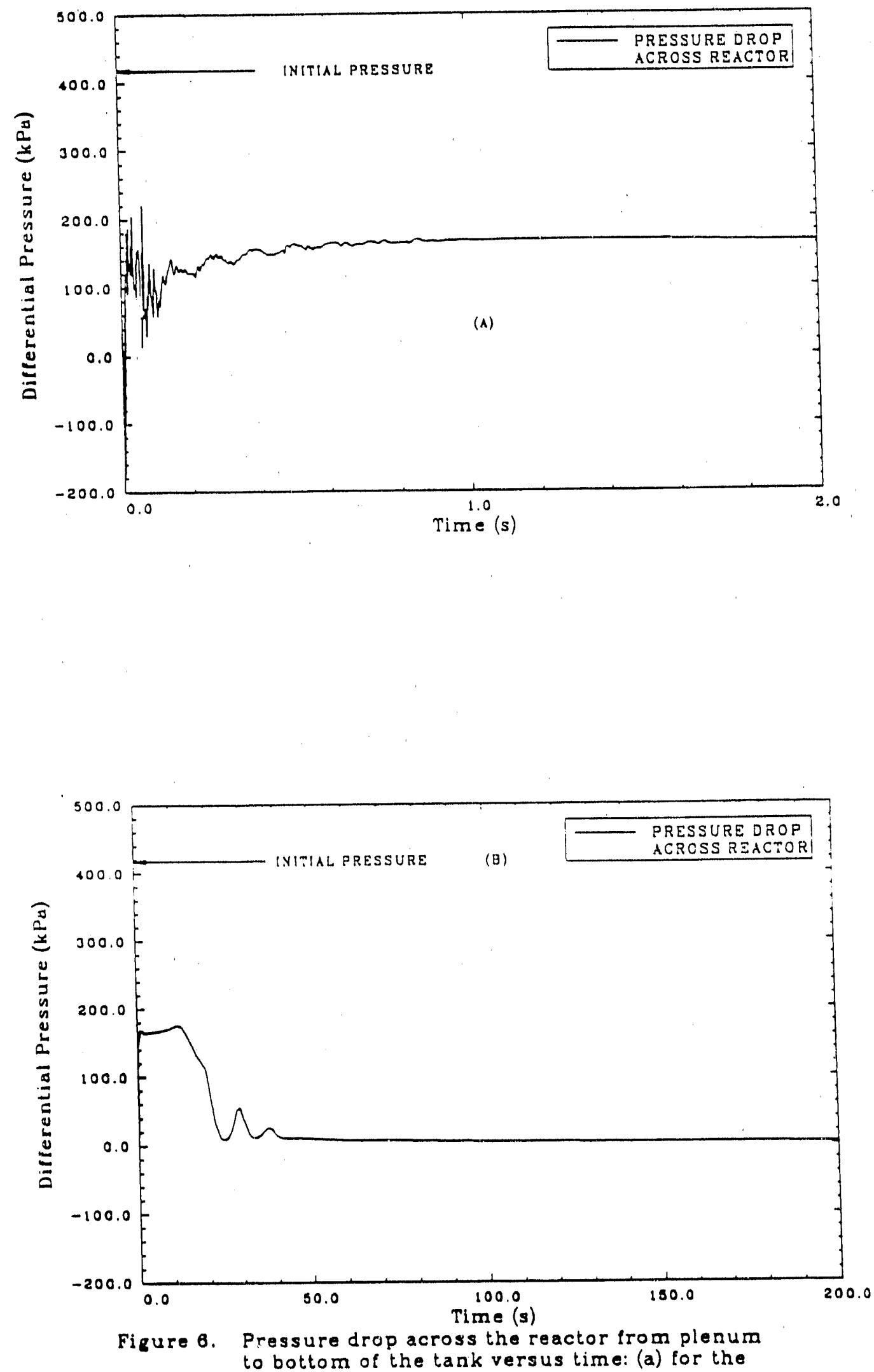
end fittings or other sections of reduced-flow areas such as pressure plate orifices and sleeve housing shell holes.

4 The flow through the reactor is reduced early in the transient before reactor power decreases due to a reactor trip. Thus, the reduced core flow results in higher efflueit temperatures and fuel assembly metal temperatures. The fluid and metal temperatures remain high until the safety rods enter the reactor and the power is rapidly shut down.

5 The higher effluent temperatures combined with a reduced system pressure increases the probability of cavitation at the pumps. If cavitation occurs, the primary flow would be further reduced.

Flow instability occurs first in the section of the reactor core that was served by the broken loop, because the flow reduction in that sector is most severe. Figures $7 \mathrm{a}, 7 \mathrm{~b}$, and $7 \mathrm{c}$ illustrate the occurrence of FI in such a core region. The sequence of events suggested by these figures are supported by information obtained from References 4, 5, and 6. Figure 7a shows the uneven distribution of pressure across the plenum as a consequence of the break, and the reduction of channel flow in the reactor region near the break. Figure $7 \mathrm{~b}$ depicts the occurrence of boiling in the bottom section of a fuel assembly, which further hinders the already uneven flow. Figure 7c depicts the same assembly in which boiling now occurs throughout. As a result, the flow is severely reduced, leading to the possibility of localized dryout and partial melting of that channel, given a sufficiently large initial operating power.

FI is a phenomena that will occur in an assembly at a given location in the core, that is above a threshold, fre-incident, assembly power. Currently, power limits are set to preclude the occurrence of FI, given a DEGB LOCA. Research is underway to determine if recovery from FI will occur prior to fuel damage. Determination of a safe operating power is one of the ultimate objectives to which the quantification of simulation uncertainty will contribute.

\subsection{ECS Phase SCEnaRIo}

The ECS phase of the transient begins when the moderator tank liquid reaches a $3.3 \mathrm{~m}$ $(10.8 \mathrm{ft})$ level, at which point the ECS flow is initiated. As the transient progresses, air may be introduced into the system due to inflow from the break and flow from the gas plenum through the gas-vent holes in the permanent sleeve housing holding the fuel assemblies. In addition, when the

level of the tank drops below $1.6 \mathrm{~m}(5.2 \mathrm{ft})$, experiments 7,8 indicate air begins to be aspirated into 

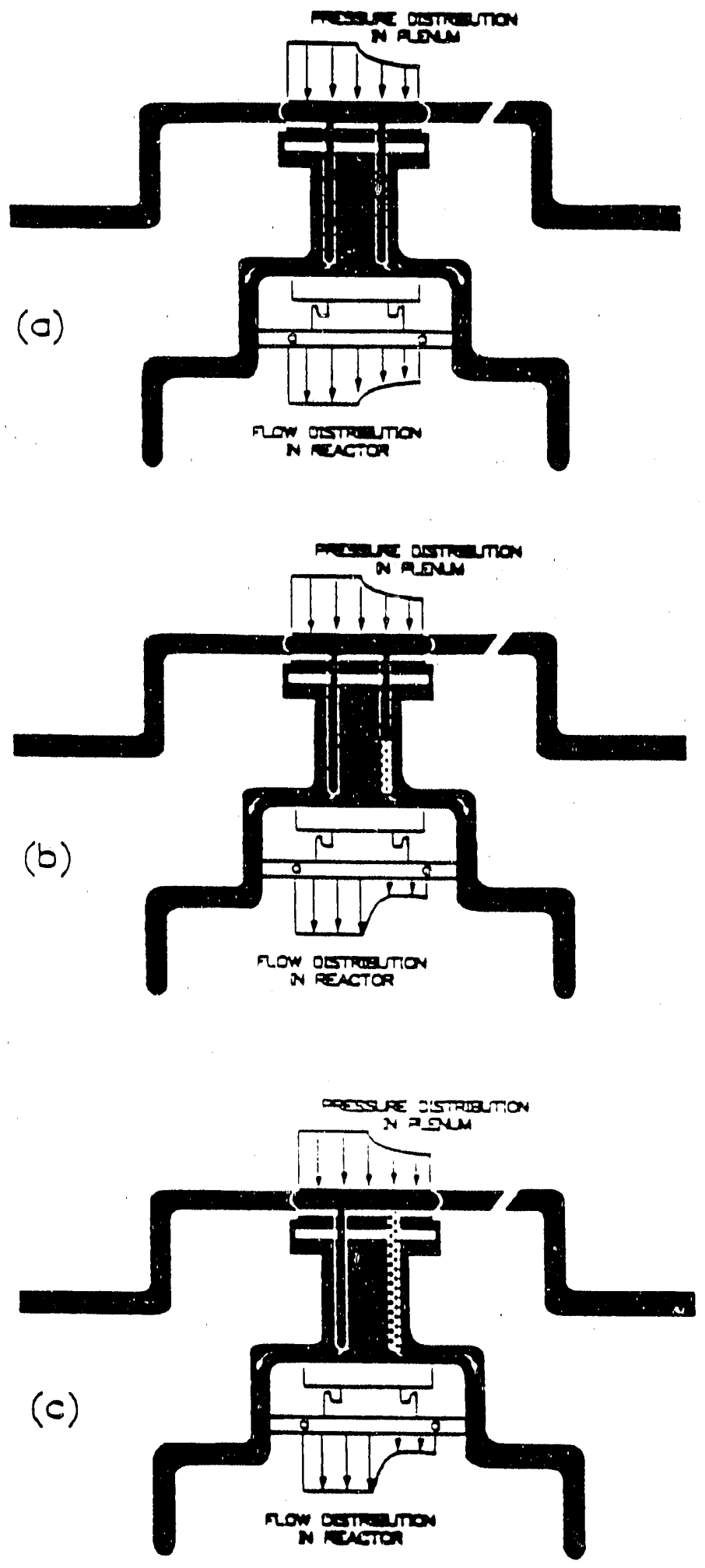

噪 Flgure 7. Fl occurence showing the uneven distribution of pressure and flow caused by (a) the breok, (b) boiling in a chand with insurficient codont flow, and (c) boiling propogating throughout the entire chamel. 
the primary cooling system by the pumps. Figure 8 illustrates this situation for a plenum inlet pipe DEGB LOCA ${ }^{3}$. Air continues to migrate through the primary cooling system, decreasing the ability of the pumps to maintain the flow of coolant, and decreasing the capacity of the coolant itself to remove heat from the reactor. Air entrainment to the fuel assembly annular channels can have the double effect of reducing the net flow of coolant through the channels, and reducing the heat transfer coefficient at the channel walls. Figures $9 a$ and $9 b$ show the history of the liquid fraction throughout the broken and intact loop, respectively. Comparison between the two indicates a slightly larger liquid inventory in the intact loops. In general, the distribution of air throughout either loop tends to become rather uniform in time.

Figures 8, and 10 through 13 are pictorial representations of the sequence of events expected to occur during the ECS phase of the DEGB LOCA. Figure 8 represents the thermal-hydraulic conditions of the system at about $12 \mathrm{~s}$. ECS has been on for about $6 \mathrm{~s}$ and the coolant pumps have just begun to aspirate air from the tank. Figure 10 represents the thermal-hydraulic conditions of the system at about $25 \mathrm{~s}$. Maximum ECS flow has been reached and air has propagated into the loops. Figures 11,12 , and 13 represent the thermal-hydraulic conditions of the system at approximately 50,100 , and $200 \mathrm{~s}$ respectively. The air eventually propagates throughout the entire system which asymptotically approaches a thermal-hydraulic equilibrium condition. At $200 \mathrm{~s}$, break flow and ECS flow are comparable in magnitude. Figure 14 shows a similar asymptotic behavior in the heat removal rate from the fuel assembly (reflection of reactor power). The system appears to have reached a stable state in which the fuel and target assemblies are adequately cooled by $200 \mathrm{~s}$.

The combination of low moderator tank level and the break in the system can result in an unfavorable distribution of coolant to the assemblies although the total flow rate of coolant delivered to the plenum has sufficiert decay heat removal capability. The low power assemblies, near the edge of the plenum, generaily receive more coolant than average, while the higher power assemblies, near the center, receive significantly less coolant than average. The key question for the ECS phase is whether or not the higher power assemblies receive an adequate share of the available coolant. If so, the reactor reaches a stable state in which long term cooling can be maintained as long as ECS functions. The accident is evencually terminated when the fuel and target assemblies are discharged from the core. 


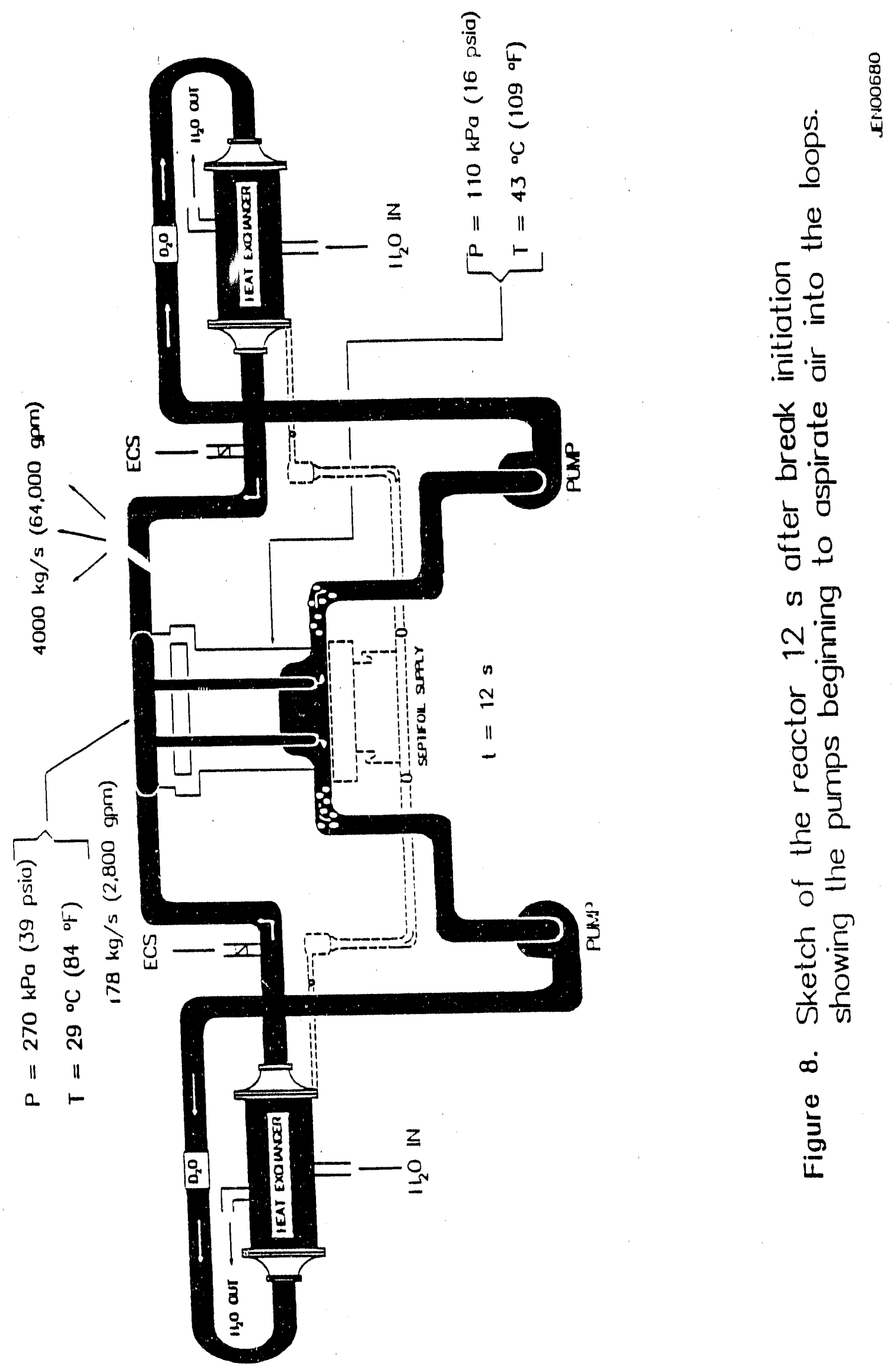



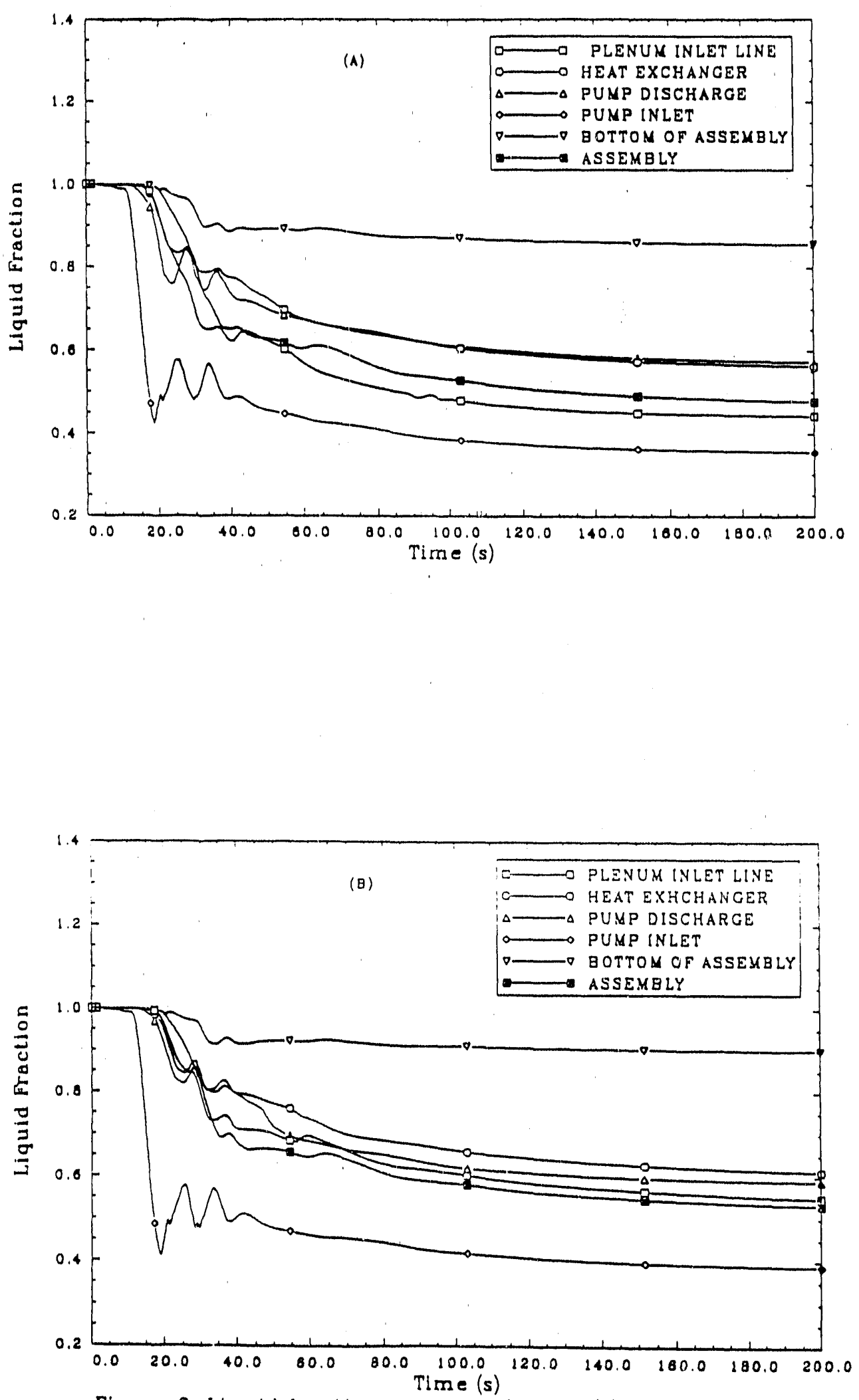

Figure 9. Liquid fraction response for the (a) broken and (b) intact loop. 


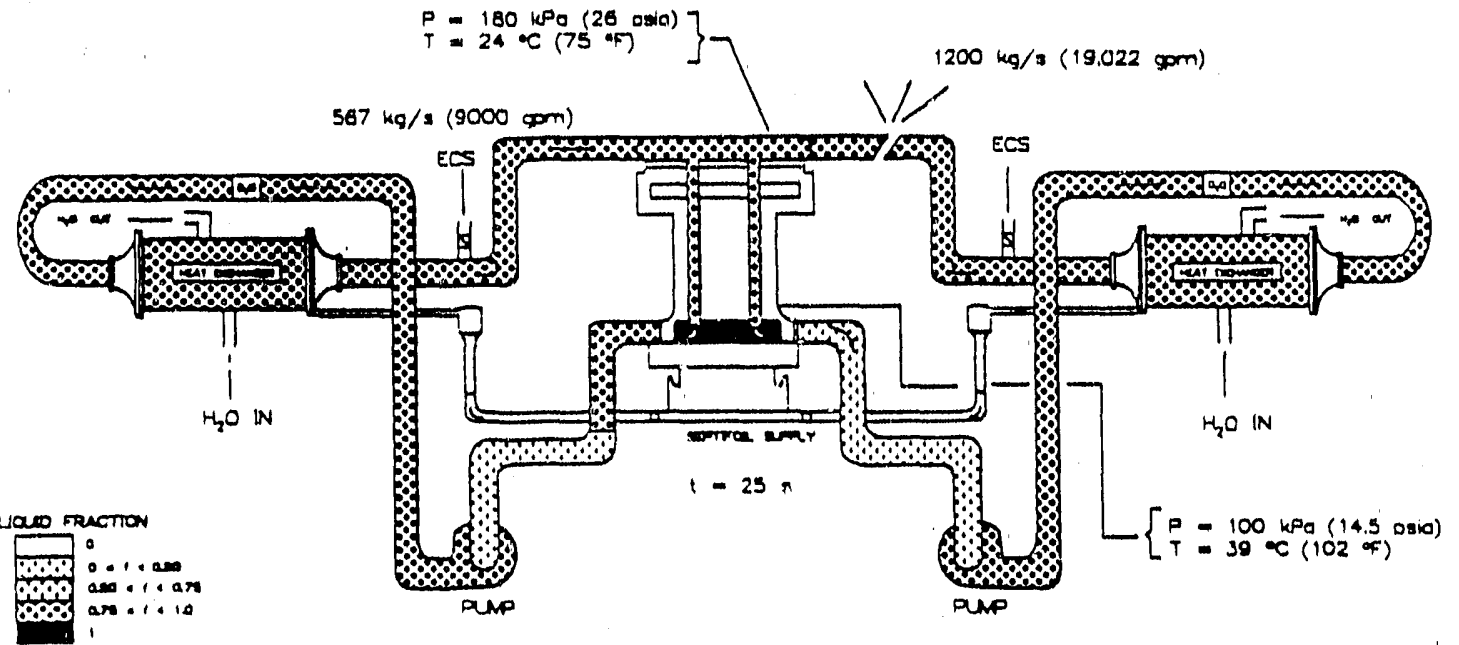

Figure 10. Skatch of the reactor 25 after braak initiation.

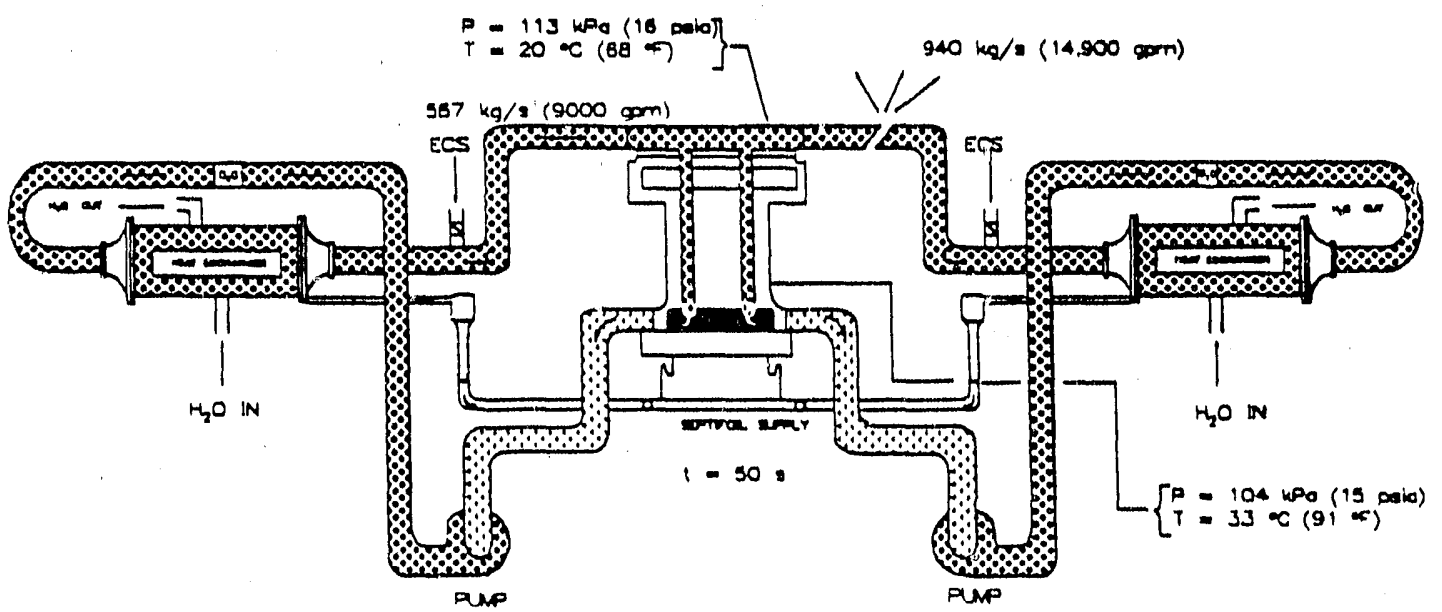

Figure 11. Sketch of the reactor 50 s after break initiation.

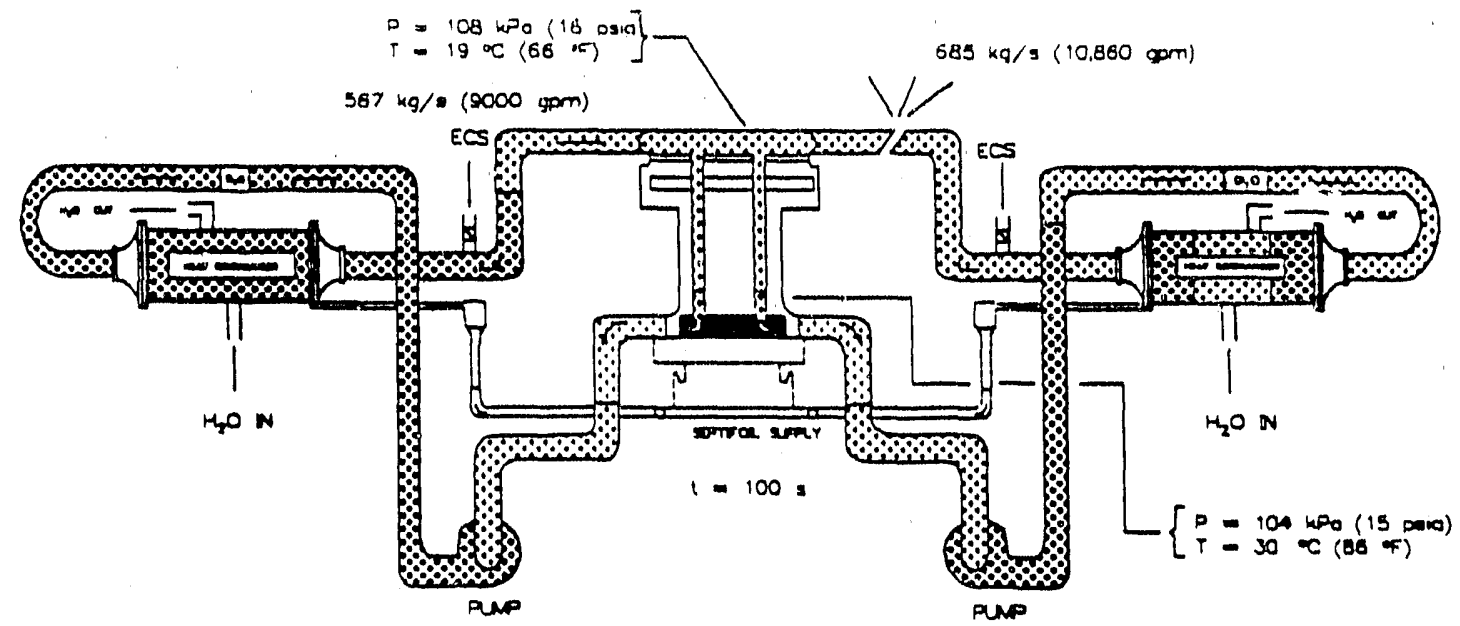

Figure 12. Sketch of the reactor 100 s after break initiation. 


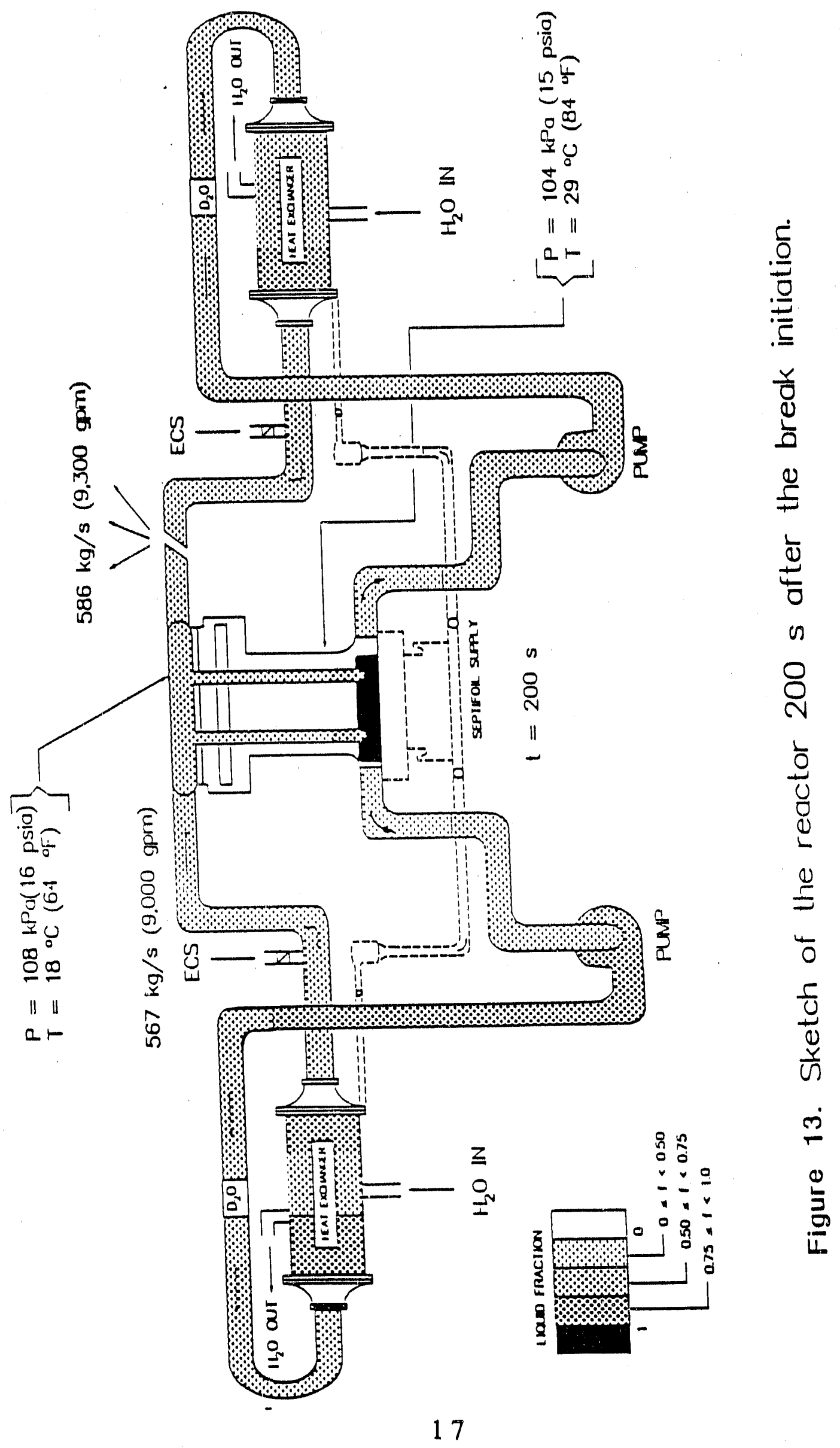




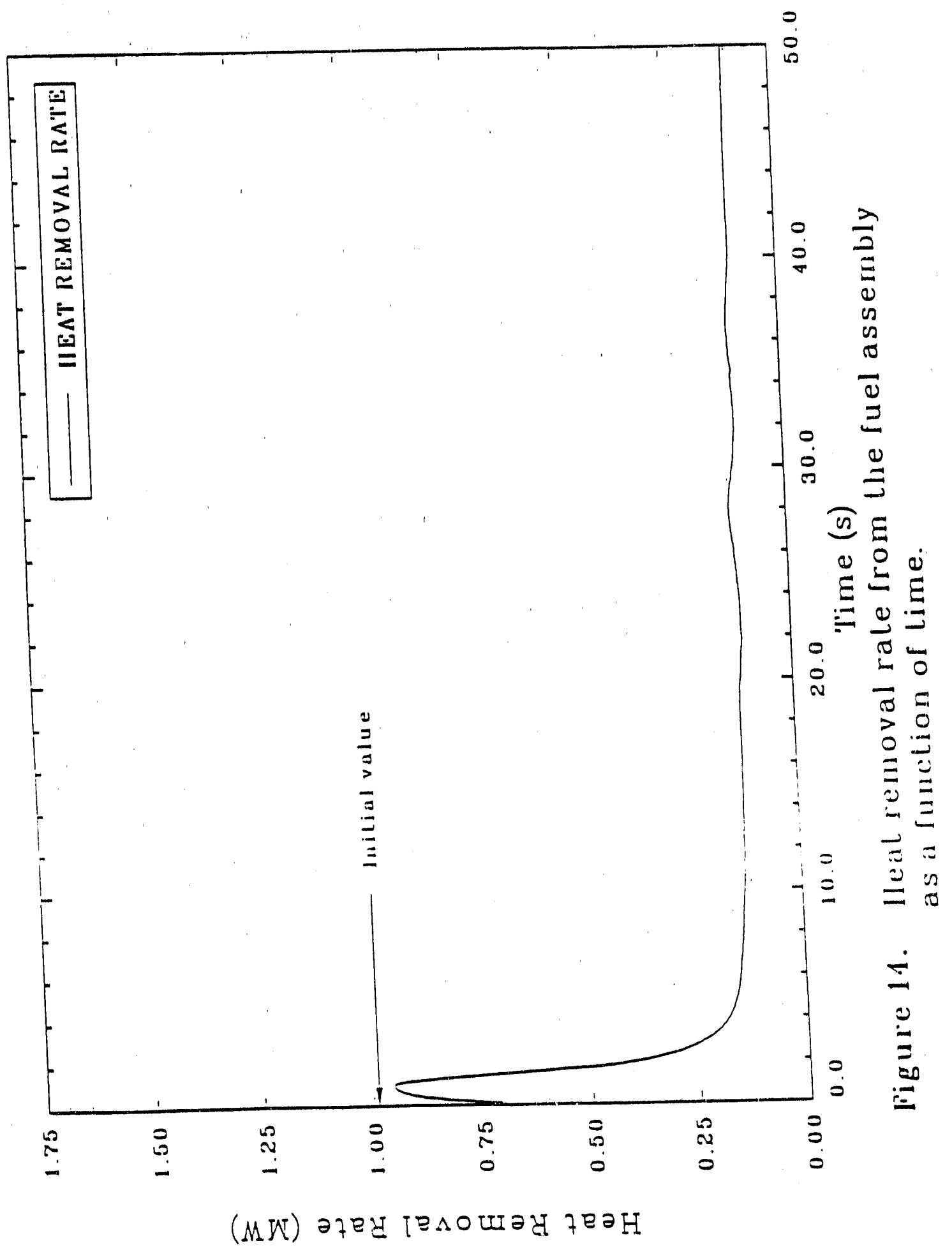




\section{PHENOMENA IDENTIFICATION AND RANKING METHODOLOGY}

This section presents the method used to identify and rank the important phenomena occurring in an SRS production reactor during the limiting DEGB LOCA transient described in Section 2. Phenomena identification and ranking was performed for the whole problem (system and fuel). It was necessary to establish the relative rankings of all phenomena in order to end up with a unified uncertainty methodology. However, since the primary focus of the CSAU project is on the system code contribution to uncertainty, the identification of fuel assembly phenomena was limited in the level of detail considered. The phenomena identification and ranking was based on safety criteria relative to the SRS production reactors. The safety criteria for the FI phase was identified by the TPG as the onset of significant voids in the fuel assemblies. For the ECS phase, safety criteria was established as the onset of dryout, defined as the point at which the fuel wall temperature is equal to the saturation temperature plus $10^{\circ} \mathrm{C}$.

Three relatively independent efforts were conducted to identify and rank the important phenomena. The first effort was conducted at the Idaho National Engineering Laboratory (INEL) using analysts experienced in commercial power and production reactor safety analyses. The second identification and ranking effort was conducted using experts from academia, industry, and the laboratories. This panel formed the Technical Program Group (TPG) charged with the direction of the limits and uncertainty program. To facilitate their effort, this panel used the INEL identification and ranking effort as a "strawman". In addition Savannah River Laboratory (SRL) provide personnel to describe plant operation and configuration details to the TPG panel. The third effort was conducted at Savannah River Laboratory (SRL) using personnel from various disciplines within the laboratory. A member of the TPG familiar with the PIRT process was provided as a facilitator to the SRL effort. The resuits of these efforts are presented in the following sections and are compared and synthesized into integrated, accurate, and complete phenomena identification and ranking tables. Appendix A summarizes the members of the three groups.

\subsection{COMPONENT IDENTIFICATION}

Once the limiting scenario was determined and the unique phases of the transient were identified, the independent review panels determined the reactor system components that were active during the transient. The component lists were generated for the FI and ECS phases. Tables 1 through 6 lists the components identified by the three panels. Tables 1,3 , and 5 present 


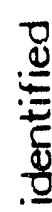
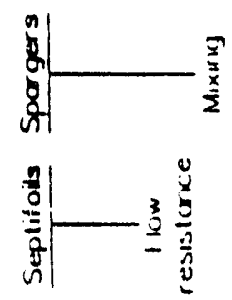

$\frac{8}{8}$

g

ป⿱艹

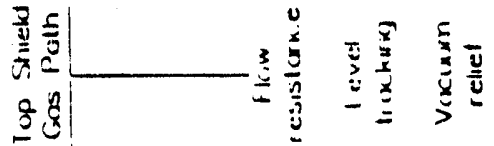

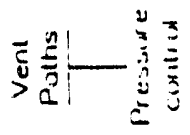

y

ڤ

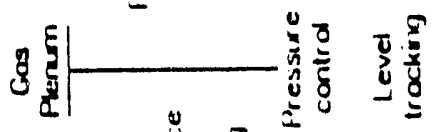

岂

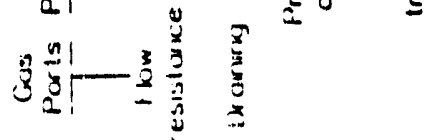

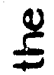

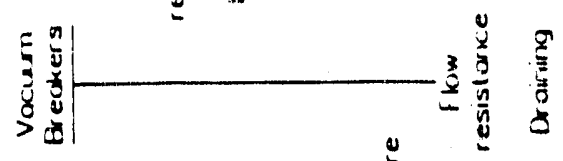

흐

完

б

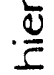

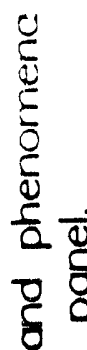

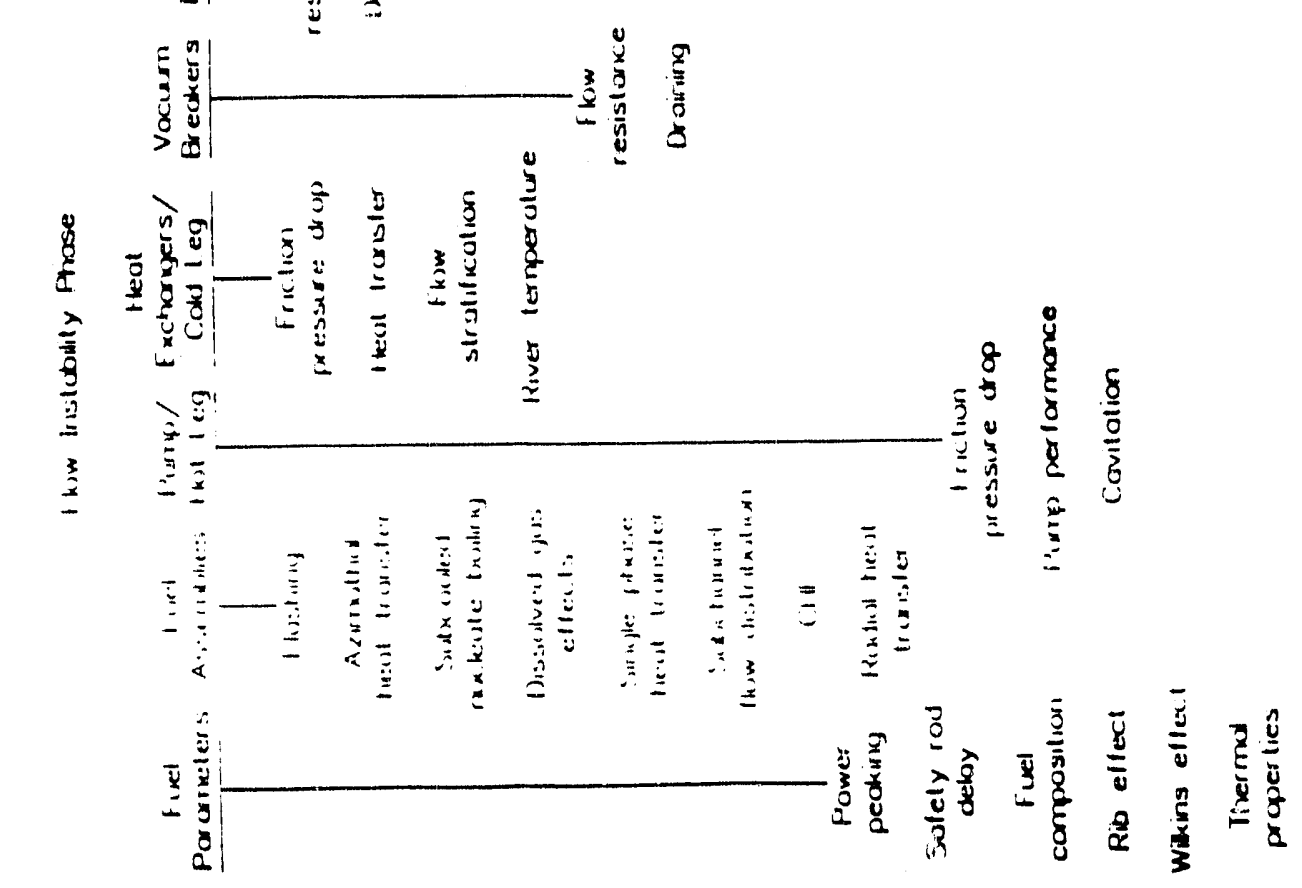

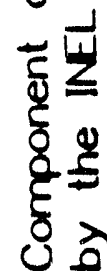

$-$

总
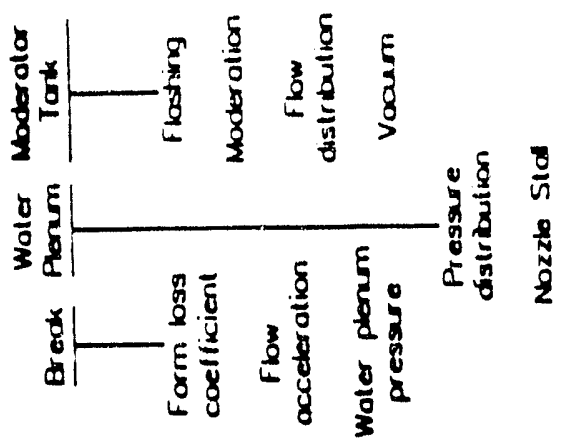

$!-=$ 


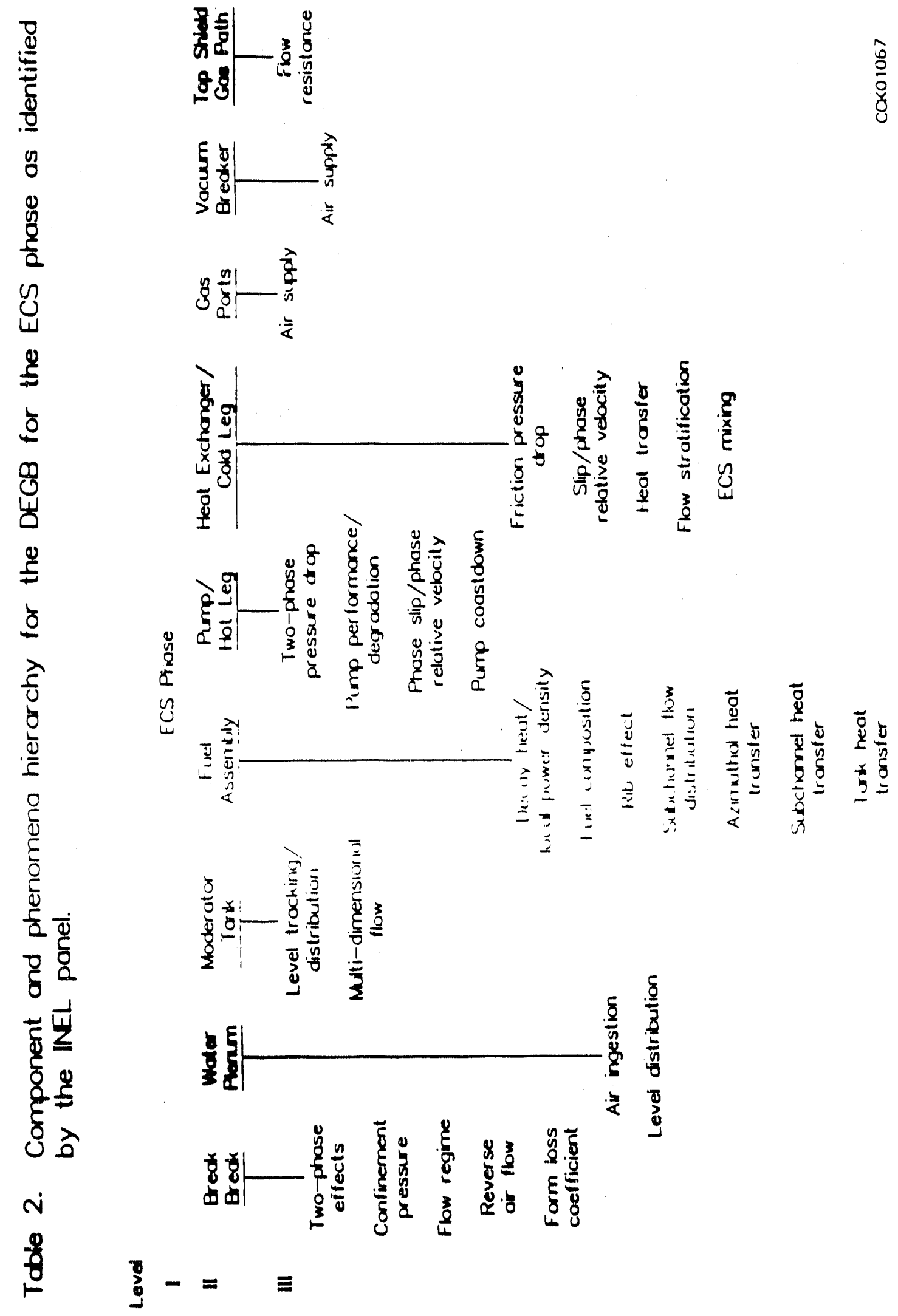




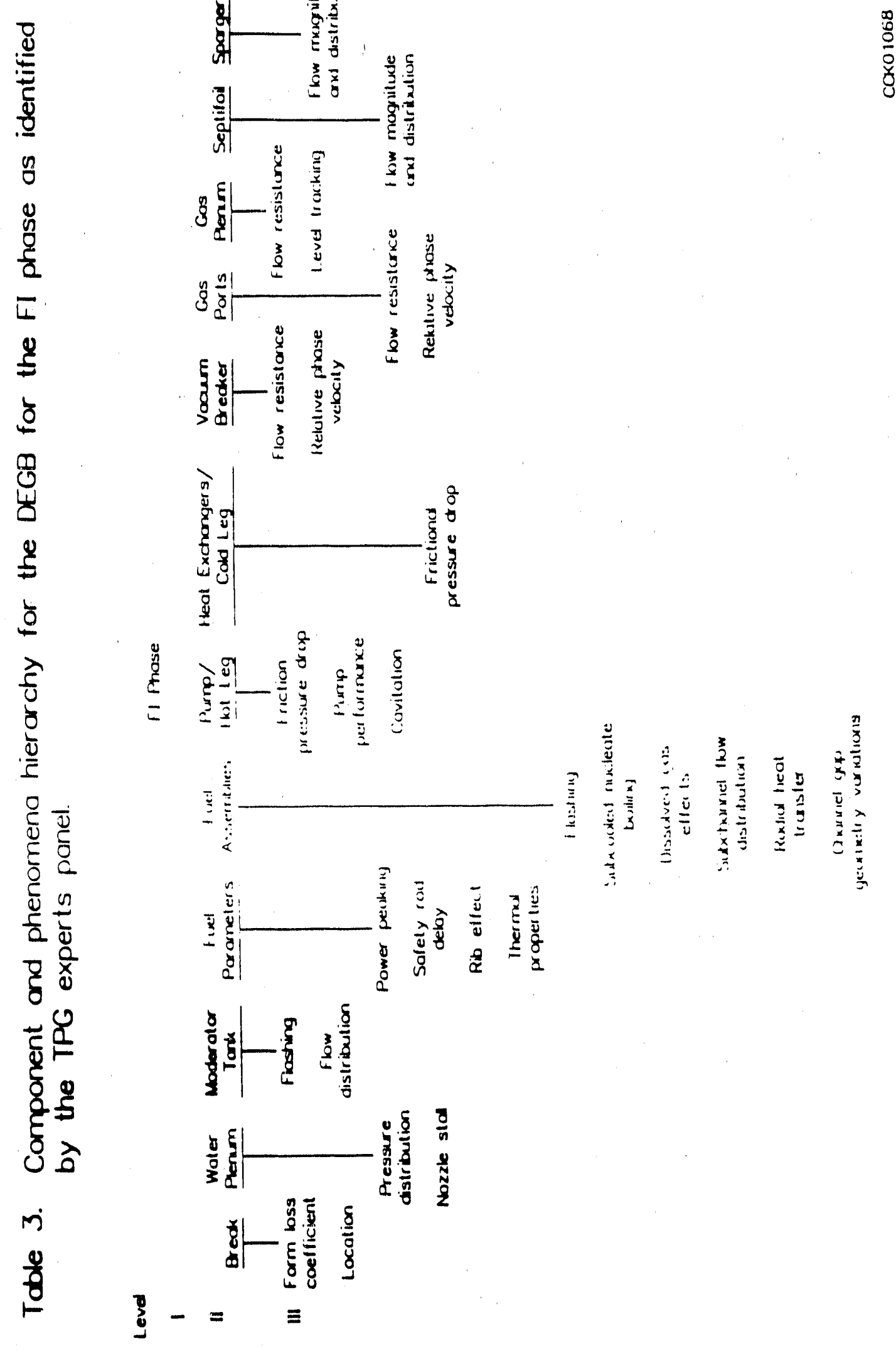


足

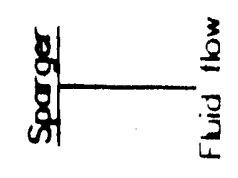

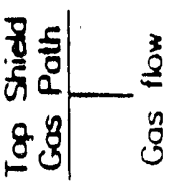

畗

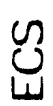

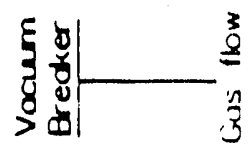

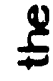

乌

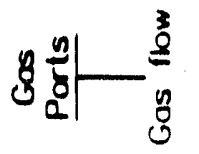

号

$\underline{\underline{y}}$

항

วิ

y

蛋

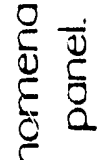

욜

든

है

案

\&

ชิ

$+$

然
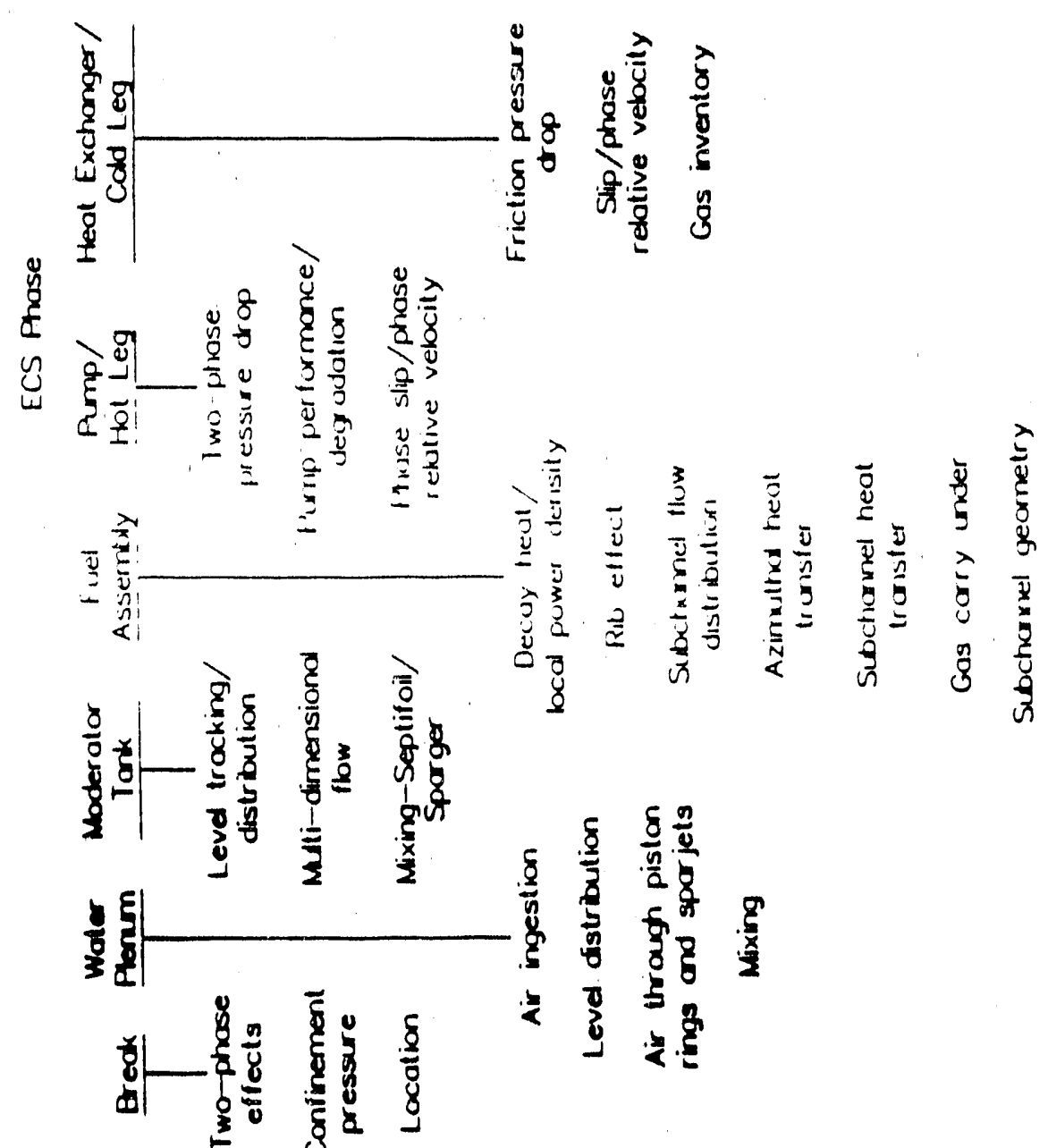

! $-=$ 
量

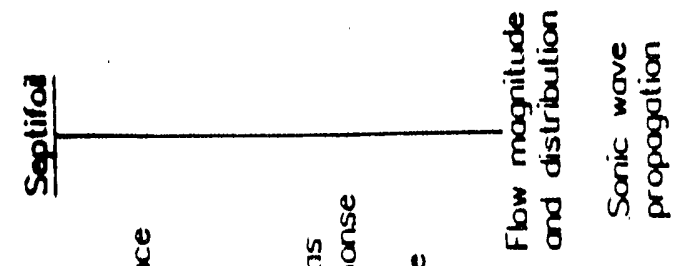

$\frac{2}{0}$

g

药

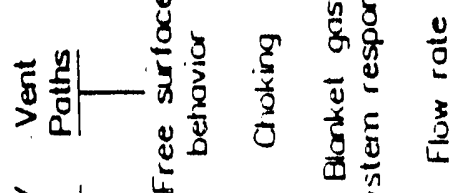

$\frac{1}{2}$

하

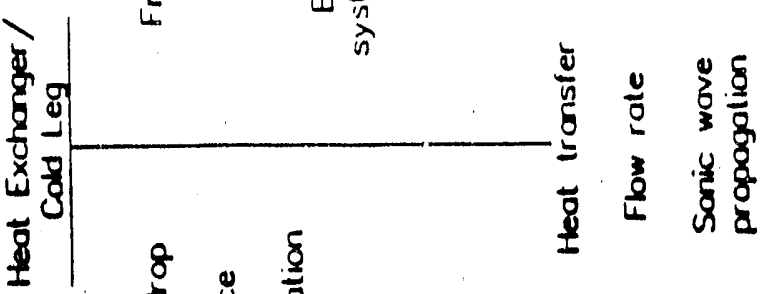

罚

Е

o

중

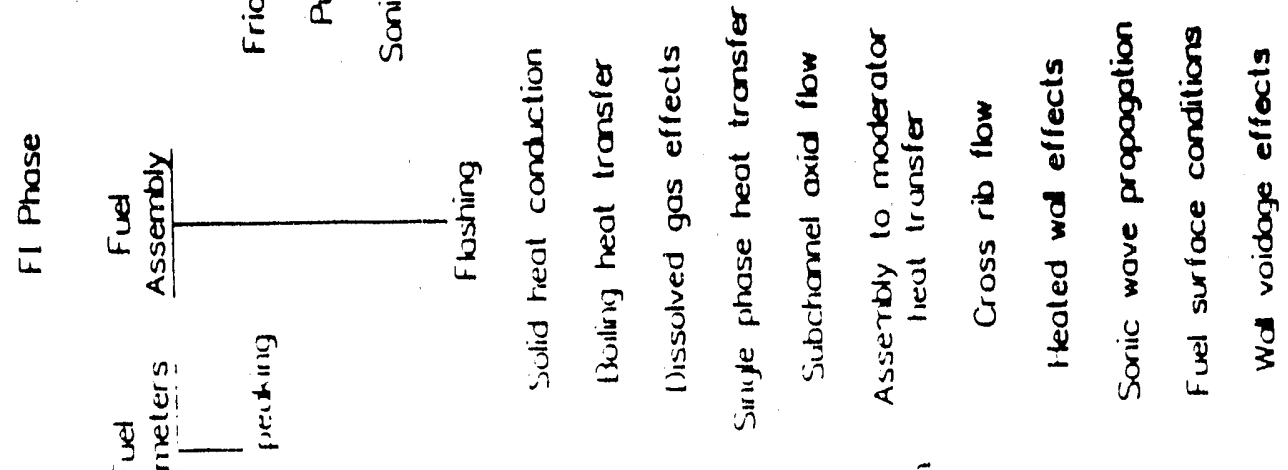

$\frac{\text { Q }}{\frac{Q}{Q}}$

है है

帝

है

เก

$\frac{8}{2}$

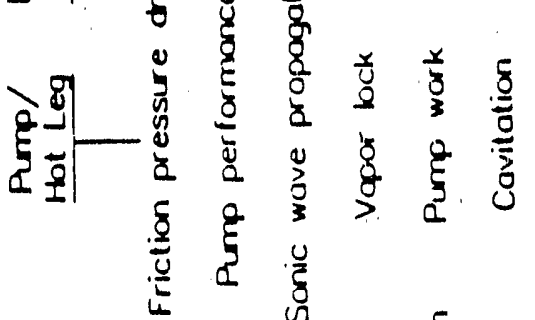

2.

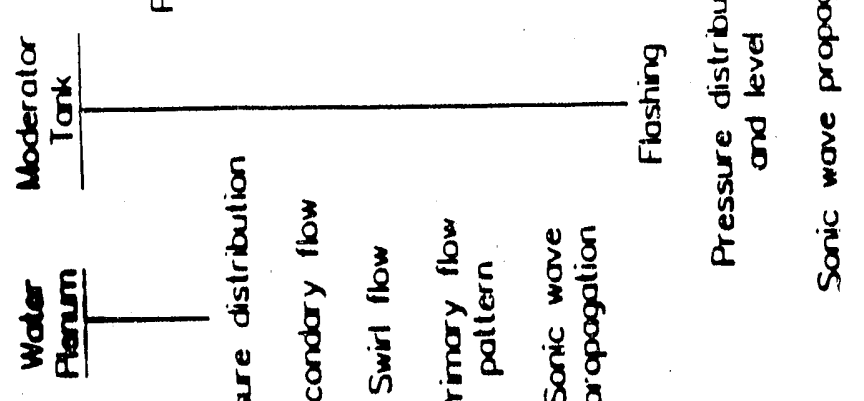

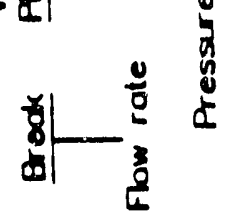

势 $-=$ 
尊

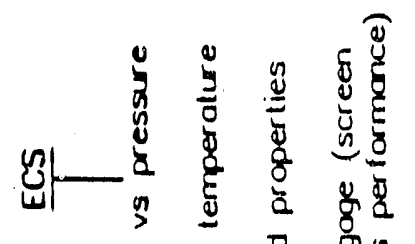

$\frac{\pi}{8}$

$g$

善

量

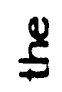

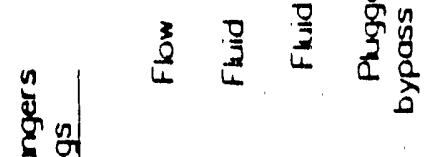

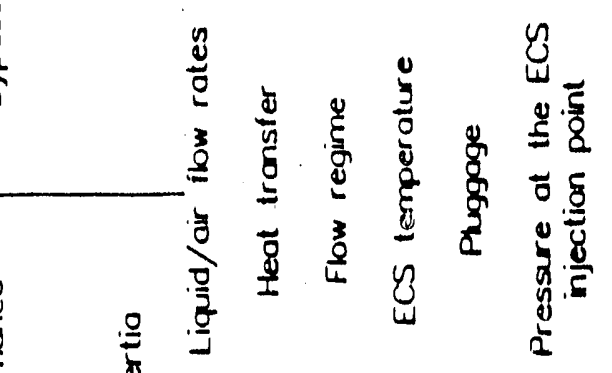

항

羃

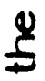

항

호․

递

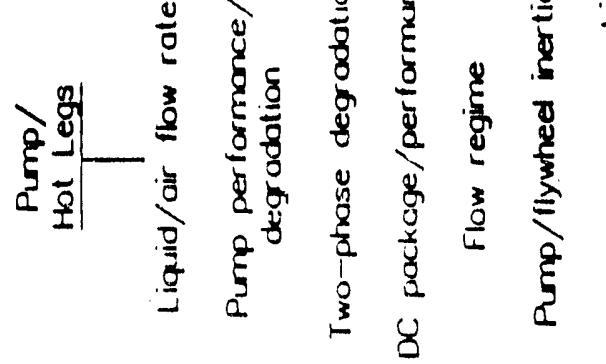

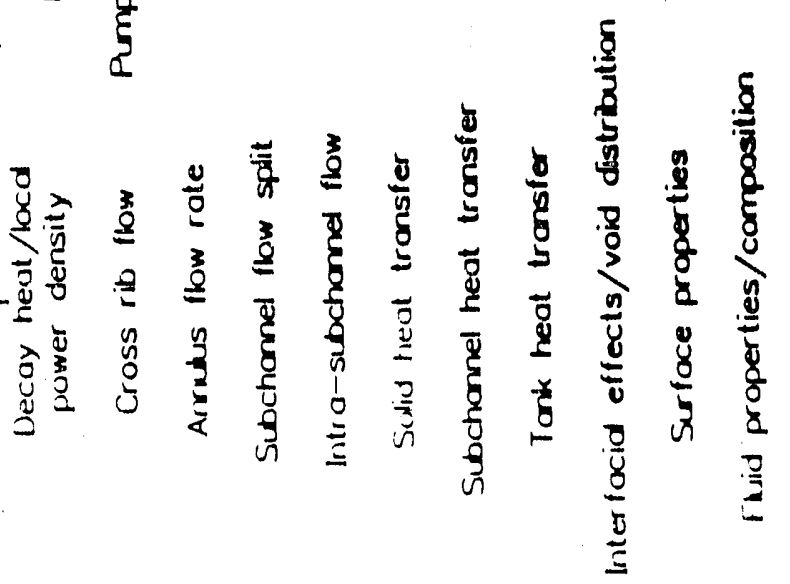

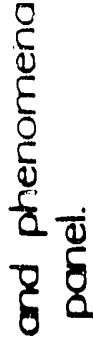

专需

है

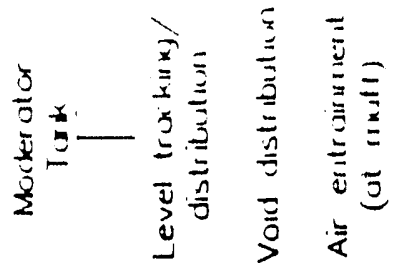

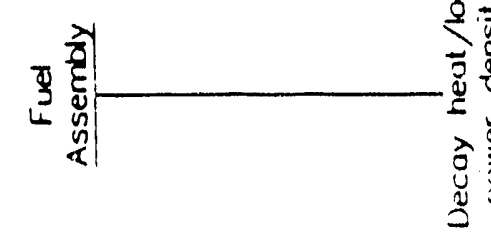

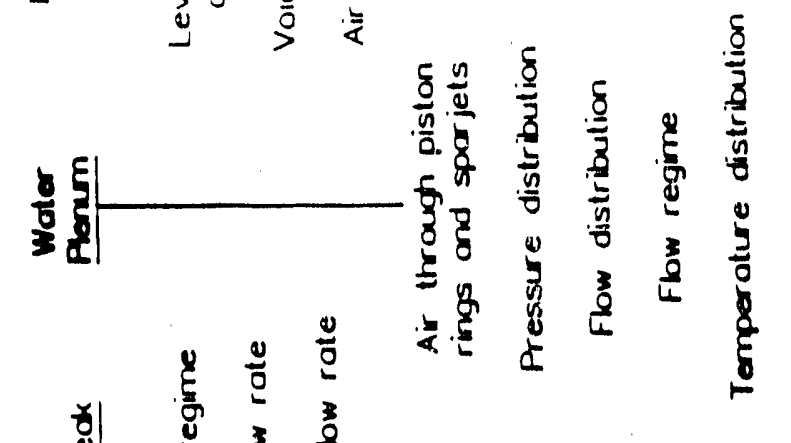

$\infty$

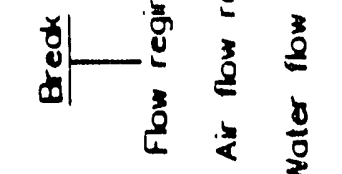

을

$$
\text { E }-=
$$


the components identified by the three panels for the FI phase. Similarly Tables 2, 4, and 6 present the components identified by the panels for the ECS phase. Comparison of the tables for the respective phases of the transient emphasizes the value of application of the method by three independent panels. Not all components were identified by each panel and therefore the parallel effort and subsequent integration provided an accurate and complete partitioning of the system into the most logical components. Appendix B presents definitions of the phenornena.

\subsection{Phenomena IDENTIFICATION}

The phenomena were identified within each comporent for the FI and ECS phases of the limiting transient. The identification of phenomena was based on experimental evidence, analytical experience, and sound engineering judgment relative to the DEGB LOCA scenario. The experimental and analytical data bases included those developed in light water reactor safety research conducted over the past twenty years. Tables 1 through $i$ identify the phenomena identified for each component by the three panels. Not all the phenomena for each component were identified by each panel. Therefore, the parallel effort provided an accurate and complete identification of the phenomena.

\subsection{IMPORTANCE ANALYSIS}

The identification of the components and related phenomena that are involved during each of the transient phases is followed by ranking of the components and related phenomena in the context of their importance to the safety criteria used to judge safe reactor operations. The first step in the importance analysis is to rank components, using engineering judgment based on experimental and analytical evidence, on a pairwise basis relative to the safety criteria for each transient phase. The results of the component ranking for both the FI and ECS phases by each of the three groups are presented in Appendix C. The second step is to rank the phenomena associated with each component on a pairwise basis for each of the phases, again, relative to the identified safety criteria and on the basis of each phenomenon's importance within the component. The two sets of ranking for each transient phase are reduced to an overall relative ranking hy using a method called the Analytical Hierarchical Process (AHP). That is, the importance of each phenomenon on a system wide basis, within the context of the safety criteria, is determined as a function of its within-component rank and the importance of the component. A detailed discussion of the AHP software and general method are given in Appendix D. 
The use of AHP for the current problem required that each phenomenon in a given component be compared to every other phenomenon occurring in the same component. The AHP process assigned a rank of 1 to 9 to each pairwise ranking. A rank of 9 meant that the first phenomenon was very much more important than the second phenomenon with regard to the acceptance criteria. For example, if safety rod delay was ranked a 9 versus power peaking, it would mean that safety rod delay was considered very much more important than power peaking with regard to the onset of flow instability during the FI phase. The AHP is a method of synthesizing the pairwise ranking to determine which variables have the highest relative importance. Judgements on the relative importance of DEGB LOCA phenomena could be made on a pairwise basis because of the capabilities of AHP. The resuit of processing the pairwise ranking with AHP is a list of all the lowest level elements ranked relative to each other on a single scale incorporating all the individual decisions made in evaluating the hierarchy. Another feature of the AHP is that it provided a measure of consistency for the subjective decisions made; too great a departure trom perfect consistency indicates a need to reconsider some of the judgements.

\subsection{Effect of Proposed System Modifications to The PIRT Process}

During the phenomena identification and ranking process, a special task force proposed several modifications to the SRS production reactors ${ }^{9}$. These changes include adding a fast shutdown system, adding a water barrier around the water plenum to maintain a liquid-full plenum at all times, adding an automatic trip of the process coolant pump ac motors, and upgrading the sump pump capability. These proposed changes were not factored into the phenomena identification and ranking process. However, it was recognized that if any of these modifications were implemented, the phenomena identification and ranking process would need to be revisited. 


\section{RESULTS OF THE PHENOMENA IDENTIFICATION AND RANKING}

This section of the report presents the results of the phenomena identification and ranking effort for the DEGB LOCA. First, the independent ranking results by the INEL, TPG, and SRLa are presented. Next the three independent rankings are integrated into an accurate and complete listing of the relative importance of each phenomenon.

\subsection{PIRT RESULTS FOR THE INDEPENDENT EVALUATIONS}

The results of the independent panel rankings of the phenomena for the FI and ECS phases are presented in Tables 7 and 8 respectively, according to the ranking methodology described in the previous paragraphs. It is noted that the phenomena shown in the tables may have rankings by one, two, or all three panels. This is the result of the independent nature of the three groups. As the tables show, the panels frequently defined phenomena in terms that were similar, but not identical. Also, phenomena defined in somewhat gross terms by a panel were sometimes broken down into more detailed terms by another. This was expected; indeed, the effort to understand and reconcile these differences enharices the value of the final product.

In general, the FI phenomena rankings of the panels were in good agreement. A few of the components having discrepancies merit discussion here, namely, the break, water plenum, vacuum breakers, gas ports, and the top shield gas paths. For the case of the the break component, both the INEL and TPG rated a break-related phenomena as important to flow instability. However, SRL ranked the break flow rate as a low importance phenomena. Discussions with SRL staff revealed that the basis for this ranking was that the phenomenon was well understood and hence would contribute little to the uncertainty in the calculated safety criterion.

The rankings are not intended to include considerations of uncertainty; rather, they should address only the importance of the phenomena to the safety criterion. Accondingly, the discrepancy between the SRL ranking and the TPG and INEL rankings was attributed to a difference of perspective on the process and the SRL ranking was not used.

a. The results of the application of the AHP software to the SRL pairwise ranking are different than those reported in the meeting minutes of the 2nd INEL. TPG meeting. The AHP was reapplied to the original SRL pairwise ranking in a manner consistent with the application to the INEL and TPG ranking. 
TABLE 7. COMPARISON OF THE INDEPENDENT IMPORTANCE RANKING RESULTS FOR THE FI PHASE OF A DEGB IN AN SRS PRODUCTION REACTOR.

Component/Phenomena

Break:

Flow rate

Flow acceleration

Form loss coefficient

Water plenum pressure

Location

Water Plenum:

Pressure distribution

Nozzle stall

Secondary flow

Swirl flow

Primary flow pattern

Sonic wave propagation

Moderator Tank:

Flashing

Moderation

Flow distribution

Pressure distribution and level

Vacuum

Sonic wave propagation

Fuel Parameters:

Power peaking

Safety rod delay

Fuel composition

Rib effect

Wilkin effect

Thermal properties

Fuel Assembly:

Flashing

Azimuthal heat transfer

Solid heat conduction

Subcooled nucleate boiling

Boiling heat transfer

Dissolved gas effects

Single phase heat transfer

Subchannel flow distribution

Subchannel axial flow

CHF

Radial heat transfer

Channel gap geometry variations

Assembly to moderator heat transfer

Cross rib flow

Heated wall effects

Sonic wave propagation

Fuel surface conditions

\author{
Ranking \\ INEL TPG SRL
}

3

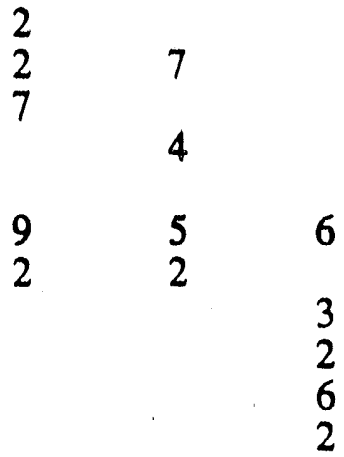

3.41

$2 \quad 2$

4

2

$\begin{array}{lll}5 & 6 & 9\end{array}$

89

42

4

$\begin{array}{lll}9 & 8 & 3\end{array}$

5

8

$8-9$

6

3

4
3
2

(n)

2

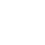

2

4

23

5

7

3

4 
TABLE 7. COMPARISON OF THE INDEPENDENT IMPORTANCE RANKING RESULTS FOR THE FI PHASE OF A DEGB IN AN SRS PRODUCTION REACTOR (CONTINUED).

Component/Phenomena

Fuel Assembly (continued):

Wall voidage effect

Pump/Hot Leg:

Friction pressure drop

Pump performance

Sonic wave propagation

Vapor lock

Pump work

Cavitation 4

Heat Exchanger/Cold Leg:

Friction pressure drop

Heat transfer

Flow stratification

River temperature

Flow rate

Sonic wave propagation

Vacuum Breaker:

Flow resistance

Draining

Relative phase velocity

Gas Ports:

Flow resistance

Draining

Relative phase velocity

Gas Plenum:

Flow resistance

Pressure control

Level tracking

Vent Paths:

Free surface behavior

Choking

Blanket gas system response

Pressure control

Flow Rate

Top Shield Gas Path:

Flow resistance

Level tracking

Vacuum relief

Septifoil:

Flow resistance

Flow magnitude and distribution

Sparger:

Sonic wave propagation

Mixing

Flow magnitude and distribution

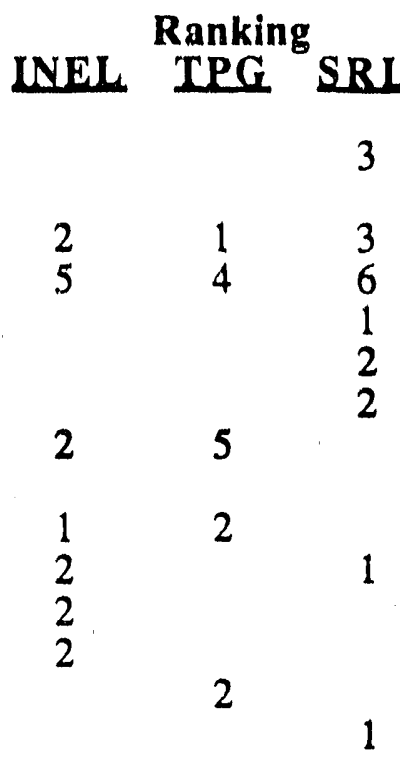

$\begin{array}{ll}7 & 1 \\ 7 & 2 \\ & \\ 7 & 1 \\ 7 & \\ & 3 \\ & 1 \\ 4 & \\ 2 & 2\end{array}$

3

4

7

7

7

2

$\begin{array}{ll}2 & 2 \\ & 1\end{array}$

2
3

3

6

2

2

1

1

2

1

3

2 


\section{TABLE 8. COMPARISON OF THE INDEPENDENT IMPORTANCE RANKING RESULTS FOR THE ECS PHASE OF A DEGB IN AN SRS PRODUCTION REACTOR.}

\section{Comnonent/Phenomena}

Break:

Two-phase effects

Confinement pressure

Flow regime

Reverse air flow

Form loss coefficient

Location

Air flow rate

Water flow rate

Water Plenum:

Air ingestion

Level distribution

Air thru piston rings \& sparjets

Mixing

Pressure distribution

Flow distribution

Flow regime

Temperature distribution

Moderator Tank:

Level tracking/distribution

Multi-dimensional flow

Void distribution

Mixing-septifoil/Sparger

Air entrainment (at muff)

Fuel Assembly:

Decay heat/local power density

Fuel composition

Rib effect

Cross rib flow

Subchannel flow distribution

Annulus flow rate

Subchannel flow split

Intra-subchannel flow

Azimuthal heat transfer

Solid heat conduction

Subchannel heat transfer

(assembly to moderator)

Tank heat transfer

(surface heat transfer)

Gas carry under

Interfacial effects/void distribution

Subchannel geometry

Surface properties

Fluid properties/composition
Ranking

INEL TPG SRL

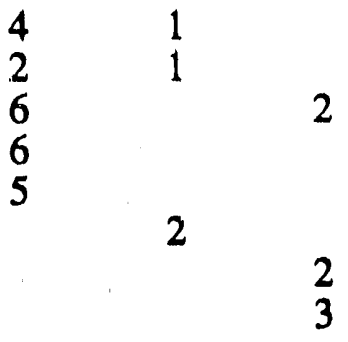

8

8

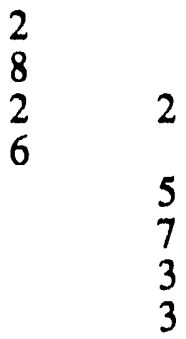

626

2

2

2

$\begin{array}{lll}6 & 3 & 9\end{array}$

3

4

9

$9-9$

42

$\begin{array}{lll}5 & 3 & 8 \\ & & 2\end{array}$

2
1

4

6

3

2

7

5

2 


\section{TABLE 8. COMPARISON OF THE INDEPENDENT IMPORTANCE RANKING RESULTS FOR THE ECS PHASE OF DEGB IN AN SRS PRODUCTION REACTOR (CONTINUED).}

Component/Phenomena

Pump/Hot Leg:

Two-phase pressure drop

Liquid/air flow rate

Pump performance/degradation

Two-phase degradation

DC package/performance

Phase slip/phase relative velocity

Flow regime

Pump coastdown

Pump/flywheel inertia

Heat Exchanger/Cold Leg:

Friction pressure drop

Liquid/air flow rate

Slip/phase relative velocity

Heat transfer

Flow stratification

Flow regime

ECS mixing

ECS temperature

Gas inventory

Pluggage

Pressure at ECS injection point

Gas Port:

Gas flow

Air supply

Vacuum Breaker:

Gas flow

Air supply

Top Shield Gas Path:

Gas flow

Flow resistance

Emergency Cooling System:

Flow vs pressure

Fluid temperature

Fluid properties

Sparger:

Pluggage (screen bypass performance)

Fluid flow

\section{Ranking}

INEL TPG SRL

21

$\begin{array}{lll}4 & 5 & 2 \\ 4 & 5 \\ & & 5\end{array}$

2

3

2

1

1

2

31

$\begin{array}{lll}1 & 3 & 2 \\ 2 & & 1\end{array}$

2

1

1

1

2

2

2

2

1

2

1

4
2
1
3 
Similarly the INEL ranked the water plenum pressure as highly important based on the importance of the plenum pressure to the calculated break flow. The INEL therefore agreed that the water plenum ranking should be more in line with the ranking provided by the TPG and SRL panels. The INEL also ranked the vacuum breakers, gas ports, and top shield gas ports as highly important to the FI phase transient outcome. However, reevaluation of the scenario suggests that FI is primarily a hydraulically dominated phenomenon. As a result, the existence of a vacuum in the top of the moderator tank momentarily during the FI phase is determined to be of low importance.

Similarly, the phenomena rankings of the panels for the ECS phase (see Table 8) were in good agreement. Noted exceptions show that the INEL ranked the break higher than did SRL and the TPG. The motivation for the medium ranking given by the INEL was that the break is the primary source of air. The INEL and $T^{T} G$ panels both considered the level distribution in the water plenum to be important while the SRL panel considered it of less importance. The level distribution was considered to be important to the proper delivery of coolant to the fuel channels.

\subsection{INTEgRated PIRT Results}

The ranking results of the three panels, for each phase of the limiting LOCA, were integrated into a single ranking for each of the identified phenomena. The integration process was performed by the TPG panel members.

The integration process proceeded as follows. A ranking of 1,2 , or 3 was considered low importance, 4, 5, or 6 medium importance, and 7, 8, or 9 high importance. Based on this criteria, the TPG evaluated each of the phenomenon and its respective rankings given by the three panels to established a single ranking. The final ranking for a phenomenon was a consensus of the TPG, but did not compromise the evaluation of the ranking by an individual panel. For example, if the rankings were 1,2 , and 3 , the final ranking would be 3 . However, if the rankings spread across the importance bounds, such as 5,5 , and 8 , the panel that ranked the phenomenon high was asked to reevaluate the phenomenon. If the panel's reevaluation still ranked the phenomenon high, the TPG gave it a high final ranking.

Table 9 presents the integrated PIRT for the FI phase of the limiting DEGB LOCA. Resolution of differences in the final ranking for the FI phase are presented in Appendix E. The table shows that the important phenomena are break flow and fuel power peaking, safety rod 
delay, fuel thermal properties, subcooled nucleate boiling in the fuel channels, and flashing in the fuei channels.

Table 10 presents the integrated PIRT for the ECS phase of the limiting transient. For the ECS phase the dominating phenomena are the mass distribution in the water plenum, fuel assembly decay heat and local power density, subchannel flow distribution, conduction heat transfer, and moderator tank level and distribution. Resolution of differences in ranking for the ECS phase are also presented in Appendix E. 
TABLE 9. COMPOSITE PIRT FOR THE FI PHASE OF THE LIMITING DEGB LOCA FOR AN SRS PRODUCTION REACTOR.

\author{
Component/Phenomena \\ Break: \\ Flow rate \\ Water Plenum: \\ Pressure distribution \\ Nozzle stall \\ Swirl flow \\ Primary flow pattern \\ Sonic wave propagation \\ Moderator Tank: \\ Flashing \\ Flow distribution \\ Sonic wave propagation \\ Vacuum \\ Fuel Parameters: \\ Power peaking \\ Safety rod delay \\ Rib effect \\ Thermal properties \\ Fuel Assembly: \\ Flashing \\ Azimuthal heat transfer \\ Subcooled nucleate boiling \\ Dissolved gas effects \\ Single phase heat transfer \\ Subchannel flow distribution \\ Radial heat transfer \\ Channel gap geometry variations \\ Assembly to moderator heat transfer \\ Cross rib flow \\ Heated wall effects \\ Sonic wave propagation \\ Fuel surface conditions \\ Wall voidage effect \\ Pump/Hot Leg: \\ Friction pressure drop \\ Pump performance \\ Sonic wave propagation \\ Vapor lock \\ Pump work \\ Heat Exchanger/Cold Leg: \\ Friction pressure drop \\ Heat transfer \\ Sonic wave propagation \\ Vacuum Breaker: \\ Flow resistance \\ Relative phase velocity
}

Rank

7

6

2

2

6

2

4

2

2 
TABLE 9. COMPOSITE PIRT FOR THE FI PHASE OF THE LIMITING DEGB LOCA FOR AN SRS PRODUCTION REACTOR (CONTINUED).

\begin{tabular}{l} 
Component/Phenomena \\
\hline Gas Ports: \\
Flow resistance \\
Relative phase velocity \\
Gas Plenum: \\
Flow resistance \\
Level tracking \\
Septifoil: \\
Flow magnitude and distribution \\
Sonic wave propagation \\
Sparger: \\
Flow magnitude and distribution
\end{tabular}

Rank
1
3
1
2
2
2
2


TABLE 10. COMPOSITE PIRT FOR THE ECS PHASE OF THE LIMITING DEGB LOCA FOR AN SRS PRODUCTION REACTOR.

\begin{tabular}{l} 
Component/Phenomena \\
\hline Break: \\
Two-phase effects \\
Containment pressure \\
Flow regime \\
Location \\
Air flow rate \\
Water flow rate \\
Water Plenum: \\
Air ingestion \\
Level distribution \\
Air thru piston rings and sparjets \\
Mixing (thermal plus density effects) \\
Pressure distribution \\
Moderator Tank: \\
Level tracking/distribution \\
Multi-dimensional flow \\
Void distribution \\
Mixing-septifoil/sparger \\
Air entrainment \\
Assembly: \\
Decay heat/local power density \\
Rib effect (cross flow blockage and \\
flow down rib) \\
Subchannel flow distribution \\
Solid heat transfer \\
Subchannel heat transfer \\
Tank heat transfer \\
Subchannel geometry \\
Surface properties \\
Interfacial effects/void distribution \\
Pump/Hot Leg: \\
Two-phase pressure drop \\
Liquid/air flow rate \\
Pump performance/degradation \\
Phase slip/phase relative velocity \\
Pump coemewn \\
Heat Exchanger/Cold Leg: \\
Friction pressure drop \\
Slip/phase relative velocity \\
Heat transfer \\
ECS mixing \\
Gas inventory \\
Pluggage \\
Pressure at ECS injection point \\
Gort: \\
Gas flow
\end{tabular}

Rank

1
1
5
2
2
3

2

8

2

6

5

6

2

1

2

4

7

9

8

4

2

2

3

6

1

4

7

4

2

2

4

1

2

3

2

1 
TABLE 10. COMPOSITE PIRT FOR THE ECS PHASE OF THE LIMITING DEGB LOCA FOR AN SRS PRODUCTION REACTOR (CONTINUED).

Comoonent/Phenomena

Vacuum Breaker:

Gas flow

Top Shield Gas Path:

Gas flow

Emergency Cooling System:

Flow vs pressure

Fluid temperature

Fluid properties

Pluggage (screen bypass performance)
Rank

2

2

4

2

3 


\section{CONCLUSIONS}

Based upon the three independent assessments of the DEGB LOCA in an SRS reactor the most important thermal-hydraulic phenomena during the FI phase of the transient are subcooled nucleate boiling and flashing in the fuel assemblies, safety rod delay, power peaking, thermal properties and fuel composition, and the flow rate at the break. During the ECS phase the important thermal-hydraulic phenomena are the level distribution in the water plenum, decay heat and local power density in the fuel, subchannel flow distribution, and solid conduction heat transfer and moderator tank level and distribution.

The three independent assessments provided a broad evaluation of the phenomena expected in the DEGB LOCA. The integration of the independent PIRTs provides an accurate and sufficiently complete identification of the phenomena and their relative importance to plant behavior, within the context of the safety criteria which will be used to help establish safe operating margins. The PIRTs will help focus the subsequent determination of the uncertainty in code simulations into a sufficient and efficient process.

In addition, the PIRTs provide an initial technical basis for judging the value (in a safety context) of potential new experimental research. A complete technical basis will be available following the subsequent completion of the remaining steps in the CSAU process. 


\section{REFERENCES}

1. K. R. Katsma, et al, Quantifying Reactor Safety Margins: Application of Code Scaling, Applicability, and Uncertainty Evaluation Methodology to a Large Break Loss of Coolant Accident, NUREG/CR-5249, to be published.

2. Limits Methodology for a Large Break LOCA in an SRP Reactor, DPSTM-110-LOCA, Draft $B$, to be published

3. C. B. Davis, Pump Cavitation in L-Reactor During a LOCA Initiated by a Large Break in a Plenum Inlet Line, EGG-EAST-8184, June 1988.

4. S. B. Aleman, L. L. Harnm, W. H. Reed, F. G. Smith, Flow Instability Analysis of a Design Basis LOCA for the L-3.1 Subcycle, NRTSC DPST-87-734, November 1987.

5. L. D. Koffman, R. E. Pevey, A. M. White, TRAC Calculations of the Initial Flow Decay in L-1.1, NRTSC DPST-87-737, December 1987.

6. A. J. Garrett, Flow Instability Limits Methodology for SRP Reactors, Safety of U-A1 Fueled Reactors Workshop, PLACE AND DATE OE EVENT!!'!!

7. D. R. Muhlbaier, Performance of Reactor Process Pumps with Starved Suction Conditions, DP-i353 UC-80, July 1974.

8. J. D. Menna, Bingham Pump Flows During LOCA Conditions for AC Motor Operation, DPST-87-704, November 11, 1987.

9. P. W. Dickson, et al, Modification Team Report - Savannah River Production Reactor Systern Approach and Hardware Modification, EGG-CNET-8439, March 1989. 


\section{APPENDIX A}

INDEPENDENT PANELS USED FOR THE IDENTIFICATION AND RANKING OF PHENOMENA FOR DEGB LOCA 


\section{APPENDIX A \\ INDEPENDENT PANELS USED FOR THE IDENTIFICATION AND RANKING OF PHENOMENA FOR DEGB LOCA}

Table A-1 lists the members of the panels at INEL, for the TPG, and at SRL that participated in the identification and ranking of the phenomena for the DEGB LOCA

\section{TABLE A-1. PANEL MEMBERS.}

INEL PANEL

C. B. Davis

R. A. Shaw

J. M. Cozzuol

P. D. Wheatley
TPG PANEL
P. Griffith (MIT)
J. Meyer (MIT)
G. Wilson (INEL)
R. Hanson (INEL)
J. Healzer (SLI)
R. A. Dimenna (INEL)a
G. Lellouche (SLI)
D. P. Griggs (SRL) $)^{b}$
J. King $(\text { SRL })^{b}$

SRL PANEL

J. P. Church (ECS only)

R. A. Dimenna (facilitator)

A. J. Garrett

D. P. Griggs (facilitator)

L. L. Hamm

B. S. Johnston (FI only)

L. D. Koffman

N. H. Kuehn

J. D. Menna (ECS only)

D. R. Muhlbaier

W. R. Reed

J. L. Steimke (ECS only)

R. A. Dimenna is now working for SRL and has been moved to the SRL panel.

b These people provided plant operation and configuration details to the TPG panel. They are not members of the TPG and did not participate in the phenomena identification and ranking process. 


\section{APPENDIX B \\ INDIVIDUAL PHENOMENON DESCRIPTION}

B-1 


\section{APPENDIX B \\ INDIVIDUAL PHENOMENON DESCRIPTION}

This is a systematic compilation of the different phenomena and parameters mentioned in the PIRT. It presents a basic definition of the phenomena, and describes their context for each of the components in which they are listed. In some cases, the parameter listed is specific of a component (i.e: Fuel Parameters). In such cases, the definition of the parameter is given in the context of its specific component, and no more description is necessary. These descriptions are listed here by phase. It is important to remember that during the FI phase, the reactor system is filled with liquid (single phase flow), and during the ECS phase, air may have been transported throughout the entire system (Two-phase flow). These lists includes only the phenomena in the integrated PIRT. Appendix E, which compares final rankings with preliminary values, includes phenomena and parameters that are not described here. In that sense, this list is a consolidated list of definitions as well.

\section{FI PHASE}

Flow Rate: Mass or volume per unit time (kg/s or GPM) of a single phase/fluid.

Break: Flow rate through the break.

Pressure Distribution: Spatial (3-D or 2-D) distribution of pressures.

Water Plenum: Radial and azimuthal distribution of pressure throughout the plenum resulting from the break, intact loops, and plenum geometry.

Nozzle Stall: Flow separation at the exit of a diverging channel or nozzle.

Water Plenum: Flow separation at the inlet nozzles.

Swirl Flow: A flow that has a predominant azimuthal velocity component.

Water Plenum: Swirl flow in the plenum.

Primary Flow Pattern: Flow pattern of the main (large scale) flow.

Water Plenum: Flow through the sleeve housing array in the plenum.

Sonic Wave Propagation: Speed of propagation of a rarefaction wave.

Fuel Assembly: Speed of propagation of the sudden depressurization through the fuel assembly.

Heat Exchanger/Cold Leg: Propagation of a rarefaction wave through this component.

Moderator Tank: Speed of propagation, throughout the tank, of the sudden depressurization caused by the initiation of the break. 
Pump/Hot Leg: Propagation of a rarefaction wave through this component.

Septifoil: Propagation of a rarefaction wave through this component.

Water Plenum: Speed of propagation, throughout the plenum, of the sudden depressurization caused by the initiation of the break.

Flashing: Sudden and spontaneous phase change (evaporation) caused by a reduction in pressure to below the saturation pressure.

Moderator Tank: The sudden depressurization initiated by the break may cause a temporary vacuum in the moderator tank. The warm liquid could then undergo some sudden evaporation to accommodate to the new conditions. The most important flashing would be in the shell holes (or in the bottom orifice plates), where the hot liquid stream attains high velocity and consequently reduced pressure.

Fuel Assembly: Spontaneous evaporation of fluid in the subchannels.

Flow Distribution: Spatial (3-D or 2-D) distribution of the flow.

Moderator Tank: Because of its internal geometry, the flow inside the moderator tank is three-dimensional.

Fuel Assembly, Subchannel: Distribution of the flow within the fuel assembly annuli and sub annuli

Vacuum: The occurrence of subatmospheric pressure.

Moderator Tank: Vacuum occurs in the top of the moderator tank, when, because of the transient initiated by the break, the pressure drops to under atmospheric values before the gas blanket system has had a chance to responded.

Power Peaking: Local variations of power above the average power of the assemblies.

Safety Rod Delay: Time delay between the activation of the scram signal and the time the rods enter the core.

Rib Effect: The preferential distribution of flow near the ribs.

Thermal Properties: Thermal Conductivity, Density, and Heat Capacity .

Fuel Parameters: Thermal conductivity, density, and heat capacity of the solid fuel.

Azimuthal Heat Transfer: Heat transfer along a circumferential path.

Fuel Assembly: Solid heat conduction along the circumference of the fuel elements.

Subcooled Nucleate Boiling: Local boiling in the warmer regions of the liquid, while the bulk of the liquid remains at temperatures below saturation.

Fuel Assembly: Local boiling at the solid fuel walls. 
Dissolved Gas Efrects: Noncondensible gases in solution in the coolant may modify the thermal properties of the coolant. Moreover, dissolved noncondensibles may come out of the solution forming bubbles that reduce the flow and the heat transfer to and from the coolant.

Fuel Assembly: Modification of heat transfer and fluid flow in the subchannels due to dissolved gases. If enough gas comes out of solution it may cause FI.

Single Phase Heat Transfer: Heat Transfer in one phase; liquid phase in the case of FI.

Fuel Assembly: Heat transfer in the coolant inside the subchannels.

Radial Heat Transfer: Heat transfer in the radial direction.

Fuel Assembly: Solid heat transfer within the fuel assembly.

Channel Gap Geometry Variations: Spatial and transient variations of the channel gap due to manufacturing tolerances and temperature changes during the transient.

Assembly to Moderator Heat Transfer: Heat transfer from the outer wall of the fuel assembly to the fluid in the moderator tank.

Cross Rib Flow: Coolant flow between adjacent subchannels separated by a rib. The flow path exists due to manufacturing tolerances.

Heated Wall Effect: Effect of wall temperature on the subchannel flow distribution. This affects the wall shear due to the differen ice in viscosities between the hot fluid next to the wall and the bulk.

Fuel Surface Conditions: Mechanical roughness of the surface and thermal properties variation.

Wall Voidage Effect: Effect of local dryout and bubble formation on the coolant flow and heat transfer.

Friction Pressure Drop: Pressure drop due to wall friction.

Heat Exchanger/Cold Leg: Differential pressure across the heat exchanger due to friction.

Pump/Hot Leg: Differential pressure in the pipe that connects the moderator tank with the pump.

Gas Plenum: Friction related flow resistance through this component.

Gas Ports: Friction related flow resistance through this component.

Vacuum Breaker: Friction related flow resistance through this component.

Pump Performance: Head vs flow characteristic of the pump.

Vapor Lock: Pump performance degradation due to an increased vapor fraction inside the pump.

Pump Work: Energy added to the coolant by the pump.

Heat Transfer: Transfer of energy (heat) by virtue of a temperature gradient.

Heat Exchanger/Cold Leg: Heat transfer between coolant and secondary system fluid. 
Relative Phase Velocity: Relative velocity of the gas and liquid phases.

Gas Ports: Relative velocity of gas and liquid flowing through these paths.

Vacuum Breaker: Relative velocity of gas and liquid flowing through this component.

Level Tracking: Location and definition of the liquid/gas-vapor interphase.

Gas Plenum: Determination of the liquid free surface in this component.

Flow Magnitude and Distribution: Volume of flow and its distribution through the different available paths.

Septifoil: Volume of flow through this component, which is diverted from the primary flow of the loops at the exit of the heat exchangers (it does not flow through the plenum nor the channels).

Sparger: Volume of flow through the sparger.

\section{ECS PHASE}

Air Flow: Mass or volume of air per unit time.

Break: Air flow in or out of the system through the break.

Gas Port, Vacuum Breaker, and Top Shield Gas Path: Gas Flow - Mass of gas per unit time allowed in or out the system through each of these vent paths.

Moderator Tank: Air Entrainment - Flow of air carried into the tank from the plenum through the subchannels, and air that enters the tank from the gas plenum.

Plenum: Air Ingestion - Air flow that enters the water plenum.

Air Through Piston Rings \& Sparjets - Air flow that enters the water plenum from the gas plenum through the piston rings and spargers.

Pump/Hot Leg: Liquid/Air Flow Rate - Two component flow through the system.

Break Location: Physical location of the break with respect to the different components of the system.

Confinement Pressure: Pressure outside of the reactor. This is the pressure that opposes the outflow through the break.

ECS Flow vs Pressure: Volumetric flow versus pressure - characteristic of the ECS pumps.

ECS Fluid Properties: Heat capacity, thermal conductivity, density, surface tension, and viscosity $\mathrm{c}$ of the ECS fluid.

ECS Fluid Temperature: Temperature of the ECS source.

Friction Pressure Drop: Pressure drop due to viscous wall friction.

Heat Exchanger/Cold Leg: Pressure drop in the piping of this component.

Flow Regime: The characteristics of the flow of liquid and gas (i.e: annular, mist, churn, stratified, etc.).

Break: Flow regime through the break. 
Fuel Assembly Decay Heat/Local Power Density: Heat released by the fuel during the long texm cooling process that follows a reactor shutdown. The local power density refers to axial/radial/azimuthal variations in power.

Gas Inventury: Amount of non-condensible fluid and vapor that builds up or is trapped in the piping.

Heat Exchanger/Cold Leg: Amount of gas in this component.

Heat Transfer: Transfer of energy by virtue of a temperature gradient.

Fuel Assembly Solid Heat Transfer: Heat conduction in the solid fuel assembly.

Fuel Assembly Subchannel Heat Transfer: Heat transfer to the coolant inside the subchannel. Fuel Assembly to Tank Heat Transfer: Heat transfer to the coolant in the moderator tank. Heat Exchanger/Cold Leg: Heat transfer between primary coolant and the secondary system.

Level Tracking Distribution: Three-dimensional shape of the liquid gas interface.

Moderator Tank: Relationship between the measured tank level and the actual shape of the liquid free surface, as determined by the nature of the flow, the internal geometry of the tank itself, and the pump suction.

Mixing: Thermal mixing of cool and hot water, as well as mass mixing of light and heavy water.

Break: Flow mixture that escapes through the break.

Heat Exchanger/Cold Leg: Mixing of ECS and primary system coolant in this component.

Moderator Tank: Mixing of coolant from different sources (Septifoil-Sparger) inside the tank.

Multidimensional Flow: Spatial (3-Dimensional) nature of the flow.

Moderator Tank: Distribution of the flow inside the tank produced by pump suction flow, sparger flow, and fuel assembly exit flow.

Pluggage: Debris introduced with the ECS flow may restrict the passage in small pipes.

ECS (Screen Bypass Performance): Debris from the ECS source be retained at the screens and restrict the ECS flow.

Heat Exchanger/Cold Leg: Pluggage in this component.

Pressure Distribution: Multidimensional pressure profile induced by the break and the ECS flow.

Break: The pressure distribution across the water plenum, due to the presence of the break and the intact loops, determines the distribution of flows through the assemblies.

Pressure at ECS Injection Point: Back pressure at the point where the ECS is connected to the primary system.

Pump Coastdown: Transient behavior of the pump performance (AC trip).

Pump Performance/Degradation: Degradation of pump performance as the fraction of air or vapor increases in the coolant. 
Rib Effects: The observed preference of the coolant to flow near the ribs. In chum flow in narrow channels, a mechanism for maintaining liquid on the heat transfer surface is a washing of the surface by liquid carried in the gas stream. This sweeping mechanism can be disrupted by the presence of ribs, hence cross flow blockage.

Slip/Phase Relative Velocity: Relative velocity of one phase with respect to the other, which influences the flow regime present.

Heat Exchanger/Cold Leg: Flow regime in this component.

Pump/Hot Leg: Flow regime in the piping of this component.

Subchannel Flow Distribution: Flow through the subchannels may vary and follow different paths.

Subchannel Geometry: Annular shape of the channels, gap tolerances, and variations between concentric and adjacent subchannels.

Surface Properties of The Fuel Assembly: Thermal conductivity, heat capacitance, density, wetting parameters, and surface roughness of the assembly material.

Two-Phase Effects: Changes or modifications due to the two-phase (gas/vapor-liquid) nature of the flow.

Break: Changes in volume flow and acceleration due to the presence of air or vapor in the fluid.

Pump/Hot Leg Pressure Drop: Friction pressure drop in the piping for two-phase flow with non-condensibles present.

Void Distribution: Distribution of non-condensible gas and vapor.

Fuel Assembly Interfacial Effects: The two-phase nature of the flow affects the heat transfer and the overall fuel assembly hydraulic response.

Moderator Tank: Void distribution in the moderator tank.

Water Flow: Mass or volume of water per unit time.

Break: Water flow through the break. 


\section{APPENDIX C}

\section{COMPONENT RANKINGS}

C-1 


\section{APPENDIX C}

\section{COMPONENT RANKINGS}

Tables C-1 and C-2 present the component rankings determined by the three independent panels for both the FI and ECS phases. The rankings were used in the application of the Analytical Hierarchial Process in conjunction with the respective phenomena ranking.

\section{TABLE C-1. COMPONENT RANKING FOR THE FI PHASE OF A LIMITING LOCA}

\begin{tabular}{|lccc|}
\hline & & \multicolumn{3}{c|}{ Relative Rank } \\
\hline Component & INEL & TPG & SRL \\
\hline Break & 7 & 6 & 2 \\
Water Plenum & 9 & 5 & 6 \\
Fuel Parameters & 9 & 9 & 9 \\
Moderator Tank & 3 & 4 & 2 \\
Pumps & 4 & 4 & 6 \\
Heat Exchangers & 2 & 1 & 1 \\
Gas Ports & 6 & 3 & 3 \\
Vacuum Breaker & 7 & 1 & 3 \\
Top Shield Gas Paths & 7 & & 3 \\
Gas Plenum & 4 & 2 & 3 \\
Blanket Gas System & 2 & & 3 \\
Septifoil & 2 & 1 & 1 \\
Spargers & 1 & 1 & \\
\hline
\end{tabular}

TABLE C-2. COMPONENT RANKING FOR THE ECS PHASE OF A LIMITING LOCA

\begin{tabular}{|lccc|}
\hline & & \multicolumn{3}{c|}{ Relative Rank } \\
\hline Component & INEL & TPG & SRL \\
\hline Break & 6 & 1 & 3 \\
Water Plenum & 8 & 8 & 6 \\
Fuel Parameters & 5 & & \\
Fuel Assemblies & 9 & 9 & 9 \\
Moderator Tank & 6 & 6 & 4 \\
Pumps & 4 & 5 & 4 \\
Heat Exchangers & 2 & 2 & 1 \\
Gas Ports & 1 & 1 & \\
Vacuum Breaker & 1 & 1 & \\
Top Shield Gas Paths & 1 & & \\
Gas Plenum & 1 & & \\
Septifoil & 1 & 1 & 3 \\
Spargers & & & \\
ECS & & & \\
\hline
\end{tabular}




\section{APPENDIX D}

\section{ANALYTICAL HIERARCHICAL PROCESS}




\section{APPENDIX D}

\section{ANALYTICAL HIERARCHICAL PROCESS}

The process of determining the most important phenomena occurring during a transient relies on engineering judgement based on experimental and analytical evidence. Engineering judgement is typically applied at the system level to determine the most significant phenomena in a complex system. The task becomes very difficult as the complexity and number of phenomena gets larger. The analytical hierarchical process (AHP) simplifies the process by requiring the analyst to make simple pairwise comparisons between candidate phenomena, each phenomenon being judged against every other phenomenon, one at a time, for its impact on a selected safety criterion. The AHP quantifies the assimilation of the pairwise decisions into a system based ranking combining the effects of all the local rankings.

The AHP facilitates a structured decision making process whereby competing variables in a complex system can be assessed against each other on a pairwise basis, and the total effect of each on a system-wide basis can be determined. The method requires that the analyst identify each element in the system to be ranked. These elements can be at different levels of significance in the system analysis. For example, a reactor transient may be divided into time intervals during which significant characteristic phenomena occur. The reactor system itself is first broken into significant components such as the steam generator, pumps, etc. Within each of the identified components, a lower level of elements is then identified as phenomena, such as boiling heat transfer or generation of voids.

At a given level, the elements are arranged into a square matrix. The value of each matrix element is the rank of one member of the matrix against another. The ranks are determined based on an arbitrary scale; such as 1-9 for which 1 implies the two items are of equal rank, 9 implies the first item is much more important than the second. When all the elements of the matrix have been filled with ranks, an eigenvector is determined. For the purpose of determining the element ranks, the principal eigenvector is used. In general, the arbitrary scale used to rank the elements against each other will not affect the ordering of the elements based on the eigenvalue of each, but the distribution of the eigenvalues will depend on the scale used, and this, in turn, can affect global ranks when the eigenvalues are used later as weighting factors to determine the relative importance of lower level phenomena. 
The arrangement of the entire analysis into a hierarchy is perhaps the most difficult part of the process, for it will affect the final results. There is no prescribed methodology by which the hierarchy can be developed. The analyst must be aware of the importance criterion chosen, and must ensure that the hierarchy will allow each of the phenomena to influence the final result with equal weight. Saaty ${ }^{1}$ gives some guidelines and examples to assist in the development of the hierarchy.

Analyzing a given problem requires first that the goal of the analysis be carefully defined. The next level represents a division of the problem into major categories used to group the various factors affecting a decision. The third level might be a further subdivision to allow local grouping of influences within the divisions described in Level 2, or it might simply be each of the candidate variables, if Level 2 represents an adequate definition of the problem. Dimenna and Larson 2 provide a simplified example of hierarchy formulation.

A few notes about the AHP are in order. First, there is no requirement that the ranks assigned to the various elements in the analysis be consistent. The typical example of inconsistent ranks is that of sports teams in which Team A can beat Team B, Team B can beat Team C, but Team C can beat Team A. A ranking to find the strongest team would rank $A$ greater than B, B greater than $C$, and $\mathrm{C}$ greater than $\mathrm{A}$. The AHP is equipped to handle this situation. It provides a measure of the consistency of the matrix by comparing the magnitude of the principal eigenvector against a consistent matrix which would give a consistency measure of zero.

A second note is that the number of elements included in a given matrix affects the global weight of each of those elements compared to the weights of elements in the other matrices at that level. This distortion introduced when different numbers of elements are in the various matrices is accommodated in the weighting procedure by normalizing the local weights in each matrix to a value of one before the weighting factors are applied.

This ensures that the most highly ranked element of each matrix takes on the weight of the matrix assigned by its elemental position in the next higher level of the hierarchy. Therefore, the highest ranked element takes on an undistorted value in the global ranking. The distortion introduced from having different numbers of elements is then taken at the low end, since the low ranked elements have their significance artificially increased by the normalizing procedure. This distortion is recognized and accepted because the principal purpose of the AHP application is to identify the highly ranked phenomena. Distortions at the low end are of little concern, since those phenomena are, in general, dismissed from further consideration in the code applicability analysis. 
Reference 1 provides information about the methodology, and Reference 2 provides a very straightforward discussion of the use of the method. 


\section{REFERENCES}

1. T. Saaty, Decision-Making for Leaders, Belmont: Lifetime Learning Publications, Wadsworth Inc., 1982.

2. R. A. Dimenna, T. K. Larson, Ranking Significant Phenomena in Physical Systems, submitted to the 1989 ANS Winter Meeting. 


\section{APPENDIX E}

\section{COMPARISON AND RESOLUTION OF RANKINGS}




\section{APPENDIX E \\ COMPARISON AND RESOLUTION OF RANKINGS}

Tables E-1 and E-2 present the final and preliminary independent ranking values and the way in which major differences were resolved for the FI and ECS phases respectively. In each case (per phase and component), the final ranking is given in bold print and the preliminary rankings, which correspond to the three independent panels (TPG, INEL, and SRL), are also listed. The absence of a numerical value indicates that the phenomenon was not considered, or was lumper within some other classification, by the group performing the ranking. An explanation of the resolution of major differences is provided immediately after the corresponding listing of the phenomenon. If all classifications indicate that the particular phenomenon is of low $(1,2$, or 3$)$, medium $(4,5$, or 6$)$, or high $(7,8$, or 9$)$ importance simultaneously, the difference is not considered major and explanation is not offered for the final ranking. The same occurs when the rankings fall in different groups of importance but the numerical difference is only $\backslash+-1$ (i.e: 5 and 6 , or 3 and 4). 


\section{TABLE E-1. COMPARISON AND RESOLUTION OF RANKINGS IN}

THE FI PHASE.

\begin{tabular}{|c|c|c|c|c|}
\hline Phenemena & $\begin{array}{l}\text { Final } \\
\text { Rank }\end{array}$ & $\begin{array}{l}\text { Indeper } \\
\text { TPG } \\
\text { Rank }\end{array}$ & $\begin{array}{l}\text { nt EV } \\
\text { INEL } \\
\text { Rank }\end{array}$ & $\begin{array}{l}\text { ations } \\
\text { SRL } \\
\text { Rank }\end{array}$ \\
\hline \multicolumn{5}{|l|}{ Component: Break } \\
\hline Flow rate & 7 & & & 3 \\
\hline Flow Acceleration & & & 2 & \\
\hline Form loss coefficient & & 7 & 2 & \\
\hline Water plenum pressure & & & 7 & \\
\hline
\end{tabular}

Resolution: Different groups independently ranked phenomena and parameters closely related to the flow rate. It was the consensus that all of these concerns could be lumped under the flow rate.

Location

Resolution: The SRL staff were cognizant of significant study which indicates an inlet plenum break as the worst location for the FI phase. Therefore, break location was eliminated as a variable for this phase.

\section{Component: Water Plenum \\ Pressure Distribution \\ 6 \\ 5 \\ 9 \\ 6 \\ Resolution: Upon discussion with the other panels, the INEL panel concluded that its preliminary ranking of this variable had been influenced by code related problems. The PIRT process is founded upon evaluations of phenomena and spesifically excludes modeling related influences. Thus, INEL reconsidered its preliminary ranking and decided to change it from high to medium importanse.}

Nozzle Stall

Swirl Flow

Secondary Flow
2

2
2

2

2

Resolution: Upon consideration, the SRL panel concluded that this effect was captured in other items. Therefore, it was deleted.

Primary Flow Pattern

Sonic Wave Propagation
6

$2 \quad 2$

6

\section{Component: Moderator Tank}

Flashing

4

4

3

2

Resolution: When a consensus was not reached among the panels on technical basis, the highest ranting was adopted. Such was the case for this phenomenon.

Moderation

1

Resolution: It was determined that not being a hydraulic phenomenon, moderation has very little impact on FI. Therefore, it was removed from this PIRT.

Flow Distribution 


\section{TABLE E-1. COMPARISON AND RESOLUTION OF RANKINGS IN THE FI PHASE (CONTINUED).}

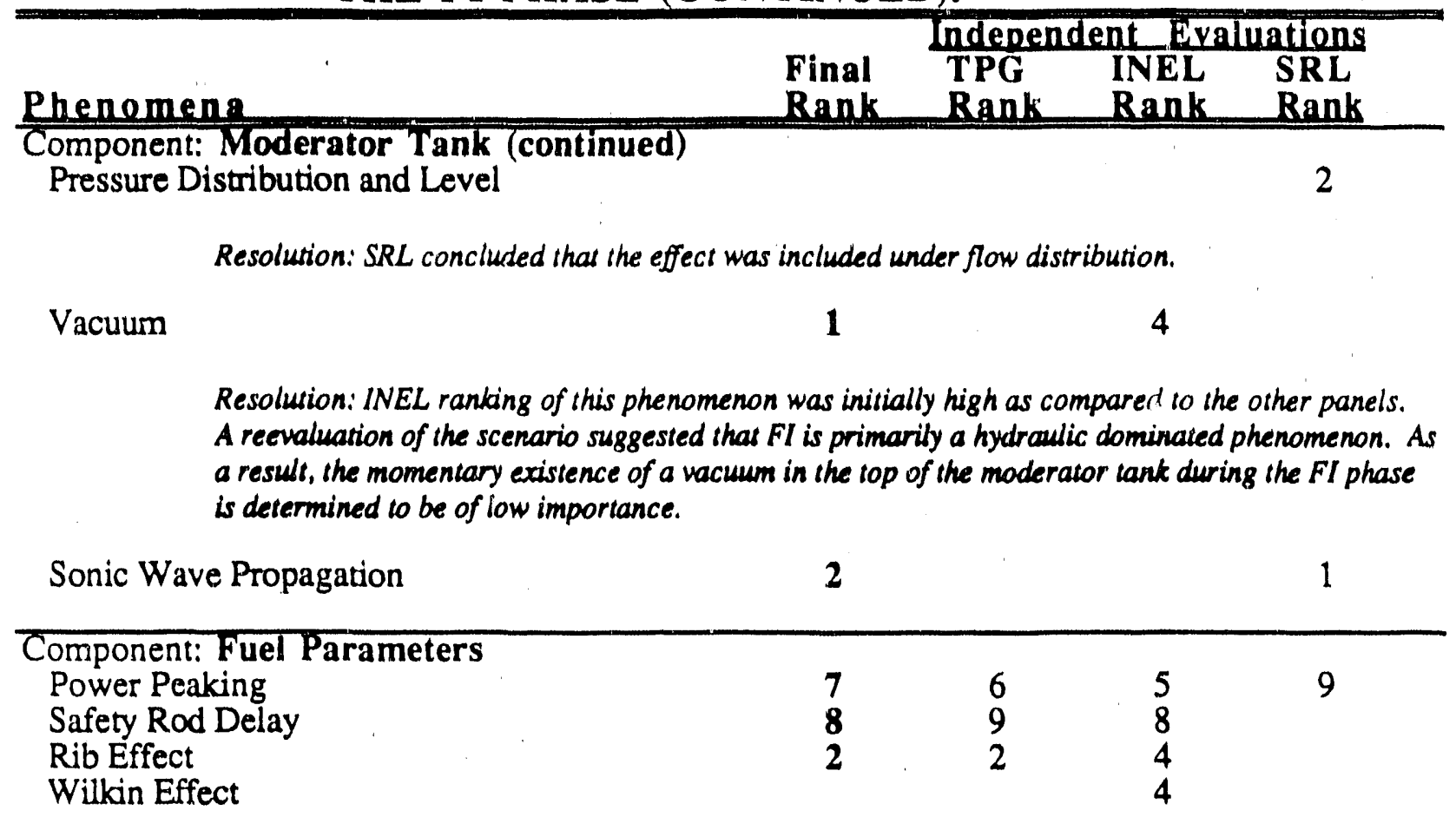

Resolution: On re-evaluation, INEL discounted any importance of this phenomena in the FI phase.

Fuel Composition

Thermal Properties
7
2
7
4

Resolution: The fisel composition and the thermal properties were combined together as thermal properties, which is now classified as a phenomenon of high importance (7).

Component: Fuel Assembly

Flashing

$8 \quad 8$

9

3

Resolution: SRL staff ranked this phenomenon low on belief that the effect was not likely during the FI phase. SRL panel agreed to high rank pending confirmation.

Azimuthal Heat Transfer

Solid Heat Conduction

Boiling Heat Transfer

Critical Heat Frux

Subcooled Nucleate Boiling
5

5
8
4

$\begin{array}{lll}9 & 9 & 4 \\ & 9 & 8\end{array}$
4

8

Resolution: The four phenomena above, from Solid Heat Conduction, were combined under of Subcooled Nuclease Boiling.

Dissolved Gas Effects

Single Phase Heat Transfer

Subchannel Axial Flow
3

6
2

2
6
3

6 
TABLE E-1. COMPARISON AND RESOLUTION OF RANKINGS IN THE FI PHASE (CONTINUED).

\begin{tabular}{|c|c|c|c|c|}
\hline Pheriomens & $\begin{array}{l}\text { Final } \\
\text { Rank }\end{array}$ & $\begin{array}{l}\text { Indepe } \\
\text { TPG } \\
\text { Rank }\end{array}$ & $\begin{array}{l}\text { nt } \text { L }_{1} \\
\text { INEL } \\
\text { Rank }\end{array}$ & $\begin{array}{l}\text { ations } \\
\text { SRL } \\
\text { Rank }\end{array}$ \\
\hline $\begin{array}{l}\text { Component: Fuel Assembly (continued) } \\
\text { Subchannel Flow Distribution }\end{array}$ & 7 & 5 & 3 & \\
\hline \multicolumn{5}{|c|}{$\begin{array}{l}\text { Resolution: Subaxial Flow was included in the interpretation of Subchannel Flow Distribution a } \\
\text { upgraded to } 7 \text {. }\end{array}$} \\
\hline $\begin{array}{l}\text { Radial Heat Transfer } \\
\text { Channel Gap Geometry Variations } \\
\text { Assmb. to Modrtr./Heat Transfer } \\
\text { Cross-Rib Flow } \\
\text { Heated Wall Effects } \\
\text { Sonic Wave Propagation } \\
\text { Fuel Surface Conditions } \\
\text { Wall Voidage Effect }\end{array}$ & $\begin{array}{l}3 \\
4 \\
2 \\
2 \\
3 \\
2 \\
3 \\
3\end{array}$ & $\begin{array}{l}3 \\
4\end{array}$ & 1 & $\begin{array}{l}2 \\
2 \\
3 \\
2 \\
3 \\
3\end{array}$ \\
\hline $\begin{array}{l}\text { Component: Pump/Hot Leg } \\
\text { Friction Pressure Drop } \\
\text { Sonic Wave Propagation } \\
\text { Vapor Lock } \\
\text { Pump Performance } \\
\text { Pump Work } \\
\text { Cavitation }\end{array}$ & $\begin{array}{l}\mathbf{1} \\
\mathbf{3} \\
\mathbf{1} \\
\mathbf{5} \\
\mathbf{2} \\
\mathbf{2}\end{array}$ & 4 & $\begin{array}{l}5 \\
5\end{array}$ & $\begin{array}{l}3 \\
1 \\
2 \\
6 \\
2\end{array}$ \\
\hline \multicolumn{5}{|c|}{ Resolution: Combined with pump performance. } \\
\hline $\begin{array}{l}\text { Component: Heat Exchanger/Cold Leg } \\
\text { Friction Pressure Drop } \\
\text { Heat Transfer }\end{array}$ & $\begin{array}{l}2 \\
2\end{array}$ & 2 & 1 & 1 \\
\hline \multicolumn{2}{|l|}{ Resolution: See Septifoil. } & & & \\
\hline $\begin{array}{l}\text { Flow Stratification } \\
\text { River Temperature }\end{array}$ & & & $\begin{array}{l}2 \\
2\end{array}$ & \\
\hline
\end{tabular}

Resolution: On reevaluation, INEL concluded the above two effects posed insignificant influence in this component.

Flow Rate

Resolution: See Septifoil. After downranking. SRL concluded that the effect was sufficiently reflected in other phenomena.

Sonic Wave Propagation 


\section{TABLE E-1. COMPARISON AND RESOLUTION OF RANKINGS IN} THE FI PHASE (CONTINUED).

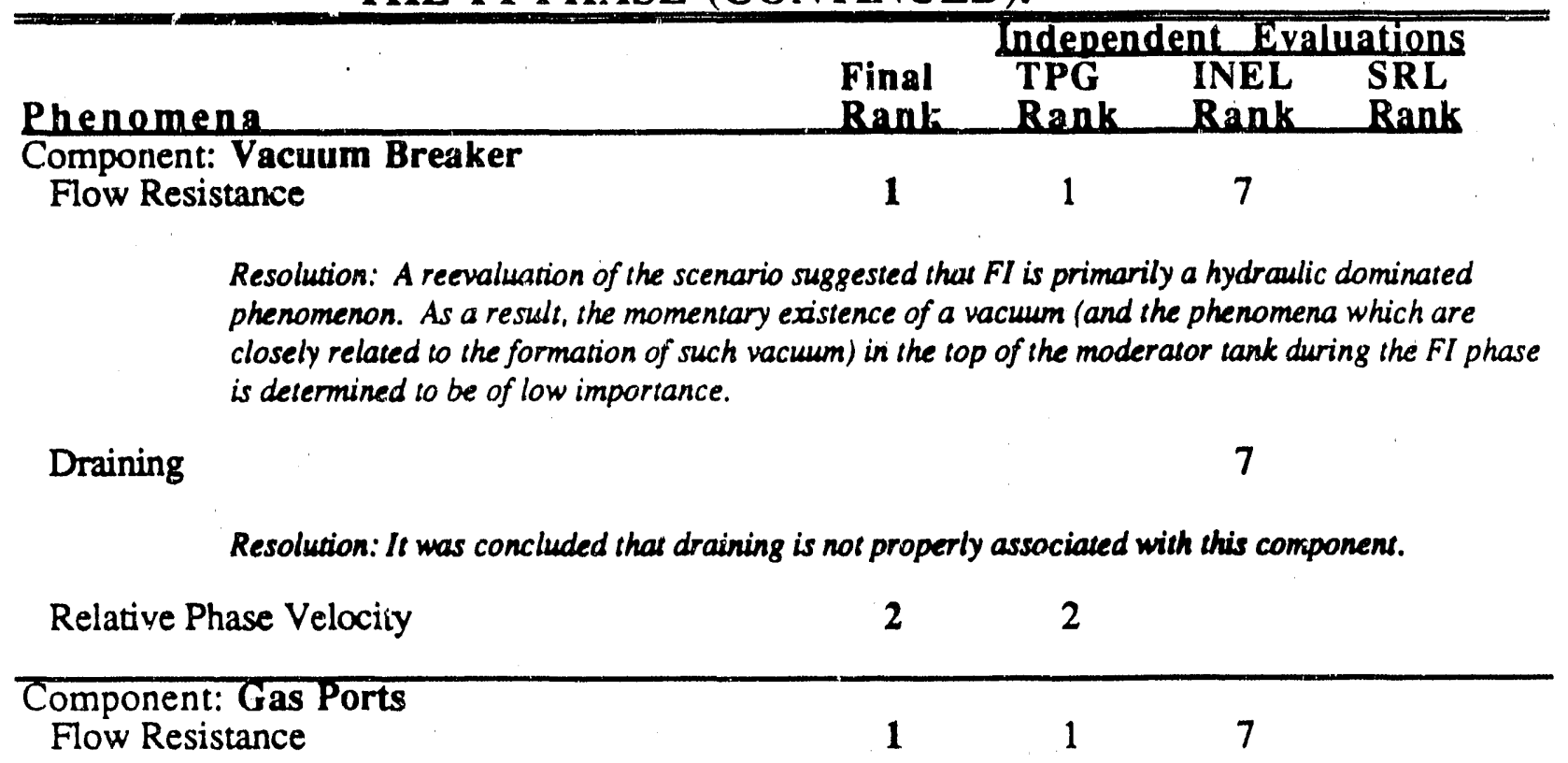

Resolution: A reevaluation of the scenario suggested that FI is primarily a hydraulic dominated phenomenon. As a result, the momentary existence of a vacuum (and the phenomena which are closely related to the formation of such vacuum) in the top of the moderator tank during the FI phase is determined to be of low importance.

Draining

7

Resolution: It was concluded that draining is not properly associated with this component.
Relative Phase Velocity
3
3

Component: Gas Plenum

Flow Resistance

Pressure Control

1

Resolusion: INEL concluded that the desired effect was embedded in flow resistance and of low imporlance.
Level Tracking
2
2
2
Cornponent: Vent Paths
Free Surface Behavior
Choking
Blanket Gas System Response
Pressure Control
Flow Rate

Resolution: Because FI is primarily a hydraulic driven phenomenon, this entire component was ultimately determined of no importance during this phase, and was removed from the FI PIRT. 


\section{TABLE E-1. COMPARISON AND RESOLUTION OF RANKINGS IN THE FI PHASE (CONTINUED).}

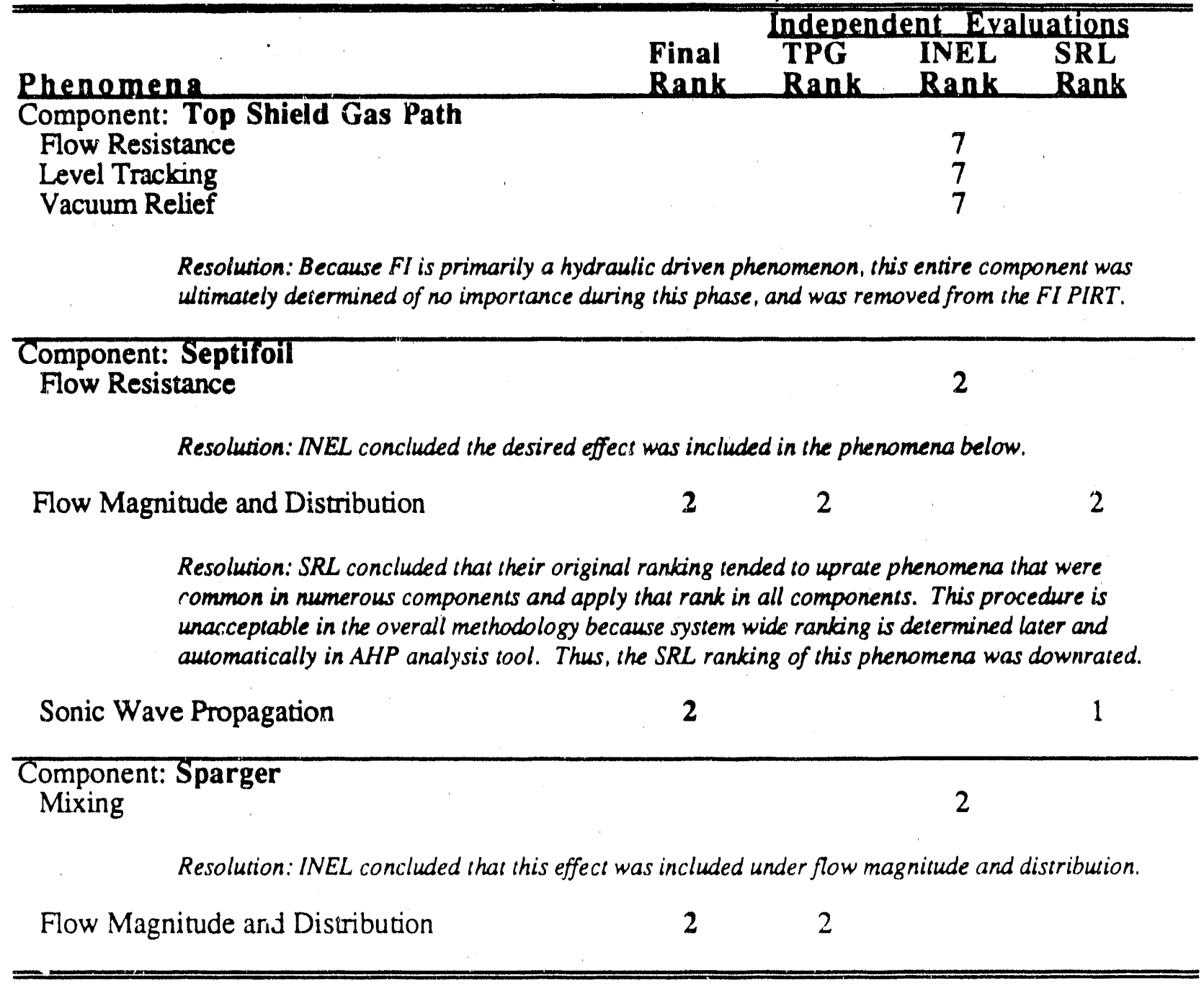




\section{TABLE E-2. COMPARISON AND RESOLUTION OF RANKINGS IN}

THE ECS PHASE.

\begin{tabular}{lcccc}
\hline & & \multicolumn{3}{c}{ Independent Evaluations } \\
Phenemeng & Final & TPG & INEL & SRL \\
Rank & Rank & Rank & Rank \\
Component: Break & 1 & 1 & 2 & \\
Confinement Pressure & $\mathbf{2}$ & 2 & & 2 \\
Location & $\mathbf{2}$ & & & 3 \\
Air Flow Rate & $\mathbf{3}$ & & 6 & 2 \\
Water Flow Rate & $\mathbf{5}$ & & 4 & \\
Flow Regime & $\mathbf{1}$ & 1 & 4
\end{tabular}

Resolution: The INEL panel agreed that the medium importance given to two-phase effects could be captured in the flow regime.

Reverse Air Flow

Resolution: The consensus was that the effect could be captured and ranked as a function of Flow Regime.

Form Loss Coefficient

Resolution: The consensus was that the effect could be captured and ranked as a function of Flow Rate.

\begin{tabular}{|c|c|c|c|}
\hline $\begin{array}{l}\text { Component: Water Plenum } \\
\text { Level Distribution } \\
\text { Air Through Piston Rings and Sparjets } \\
\text { Mixing } \\
\text { Pressure Distribution } \\
\text { Flow Distribution }\end{array}$ & $\begin{array}{l}8 \\
2 \\
6 \\
5\end{array}$ & $\begin{array}{l}8 \\
2 \\
6\end{array}$ & 8 \\
\hline Resolution: It was concluded inat & $p$ w & ted $\mathrm{s}$ & pre. \\
\hline Air Ingestion & 2 & 2 & 8 \\
\hline
\end{tabular}

Flow Regime

Resusion: It was concluded that the effects to which this phenomenon alludes are taken into account under pressure and level distribution.

Temperature Distribution

Resolution: It was concluded that the effects to which this phenomeron alludes are taten into accouns under mixing. 


\section{TABLE E-2. COMPARISON AND RESOLUTION OF RANKINGS IN THE ECS PHASE (CONTINUED).}

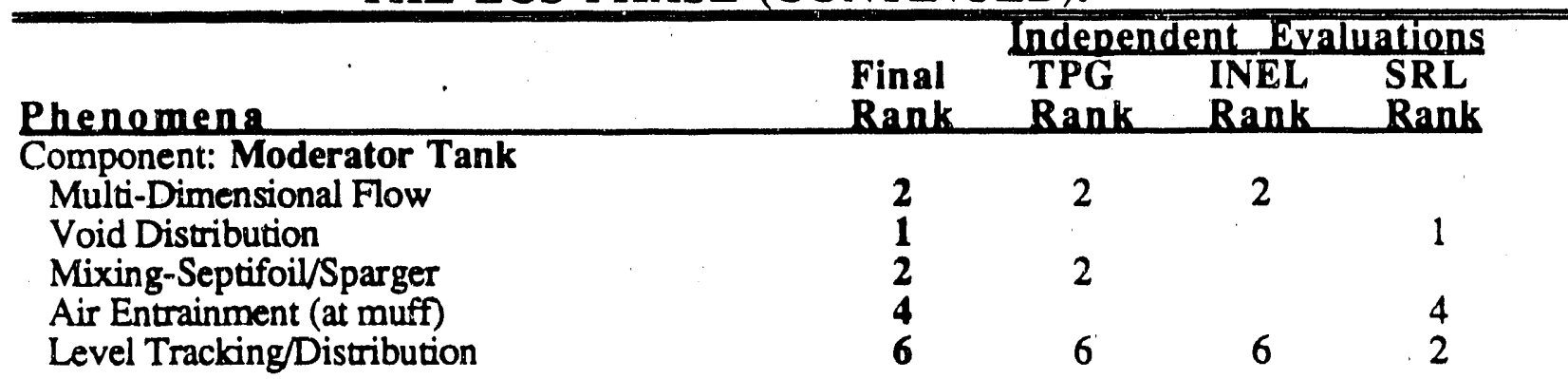

Resolution: Lack of consensus resulted in medium ranking of this phenomenon.

\begin{tabular}{lllll}
\hline Component: Fuel Assembly & 8 & & & 8 \\
Solid Heat Transfer & 4 & 3 & 5 & 2 \\
Subchannel Heat Transfer & & 2 & 4 &
\end{tabular}

Resolution: Azimuthal heat transfer was lumped under subchannel heat transfer.

Interfacial effects/Void

Distribution

Surface Properties

Tank Heat Transfer

Decay Heat/Local Power Density

$\begin{array}{llll}6 & & 6 \\ 3 & & & 3 \\ 2 & & 2 & 4 \\ 7 & 3 & 6 & 9\end{array}$

Resolution: Lack of consensus resulted in the high ranking of this phenomena.

Subchannel Geometry

Rib Effect

22

$6 \quad 7 \quad 2$

Resolution: Lack of consensus resulted in the high ranking of this phenomena.

Cross Rib Flow

Annulus Flow Rate

Subchannel Flow Split

Intra-Subchannel Flow

Gas Carry Under

Fuel Composition

Fluid Properties/Composition

Subchannel Flow Distribution

\begin{tabular}{|c|c|}
\hline 5 & 3 \\
\hline 9 & 9 \\
\hline
\end{tabular}

Resolution: It was concluded that a combination of the subchannel flow distribution, subchannel flow split, gas carry under, cross rib flow, annulus flow, intra-subchannel flow, fuel composition, and fluid properties/composition, all under subchannel flow distribution was appropriate.

\section{Component: Pump/Hot Leg}

Two-Phase Pressure Drop

Liquid/Air Flow Rate

Pump Coastdown

Phase Slip/Relative Velocity

$\begin{array}{llll}1 & 1 & 2 & 2 \\ 4 & & 1 & \\ 2 & 3 & 2\end{array}$




\section{TABLE E-2. COMPARISON AND RESOLUTION OF RANKINGS IN THE ECS PHASE (CONTINUED).}

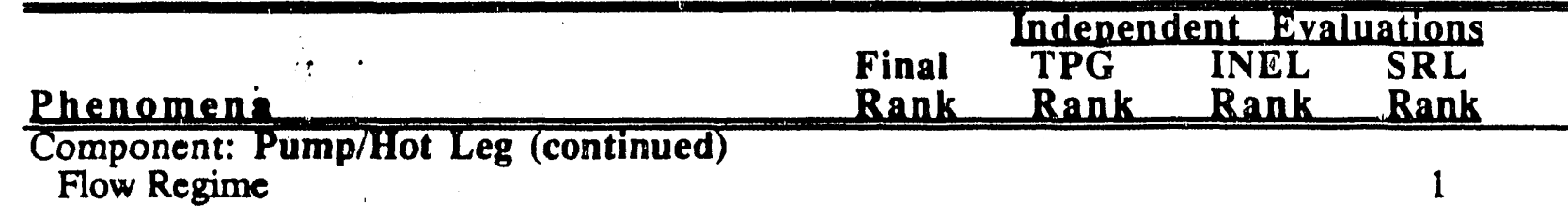

Resolution: Flow regime was lumped with phase slip/relative velocity, which resulted in a medium ranking for the latter.

Pump Performance/Degradation

7

5

4

3

Pump/Flywheel Inertia

Two-Phase Degradation

5

DC Package Performance

2

Resolution: It was the consensus that the effects of pump/flywheel inertia, two-phase degradation. and $D C$ package performance were included with pump performance degradation, at a high importance ranking, and with pump coasidown.

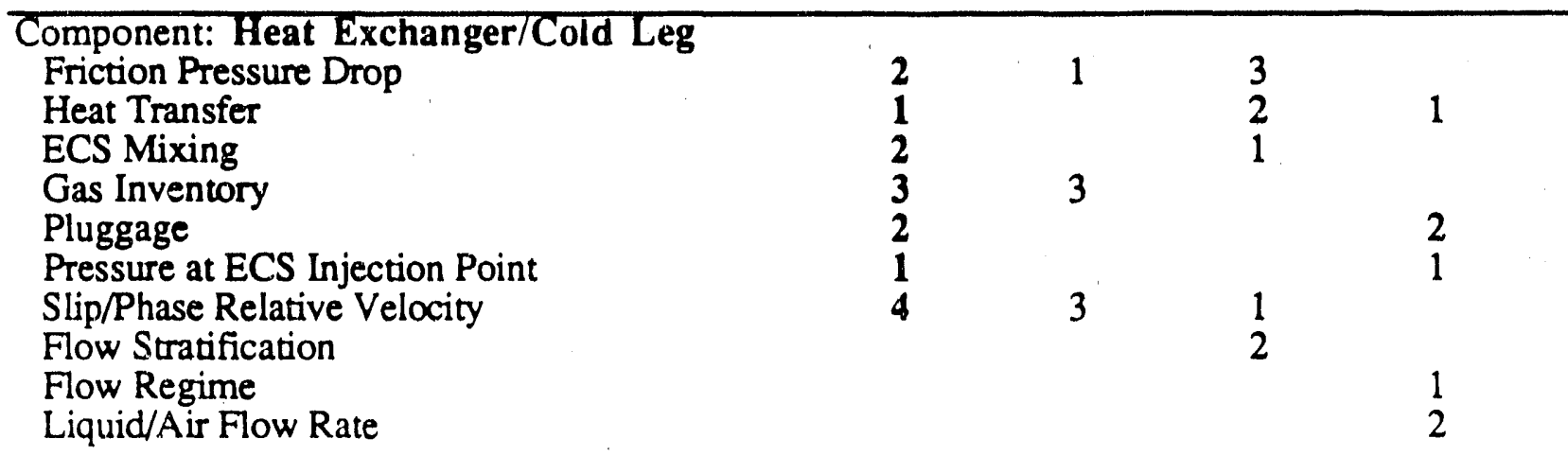

Resolution: The consensus was that the effects of flow stratification, flow regime, and liquidlair flow are included under slip/phase relative velocity, which was given a medium ranking.

ECS Temperature

Resolution: This phenomenon is now included with mixing.

\begin{tabular}{|c|c|c|c|}
\hline $\begin{array}{l}\text { Component: } \\
\text { Gas Flow } \\
\text { Air Supply }\end{array}$ & 2 & 2 & 2 \\
\hline \multicolumn{4}{|c|}{ Resolution: INEL definition of air supply is included in Gas Flow. } \\
\hline $\begin{array}{l}\text { Component: } \\
\text { Gas Flow } \\
\text { Air Supply }\end{array}$ & 2 & 2 & 1 \\
\hline
\end{tabular}

Resolution: INEL definition of air supply is included in Gas Flow. 
TABLE E-2. COMPARISON AND RESOLUTION OF RANKINGS IN THE ECS PHASE (CONTINUED).

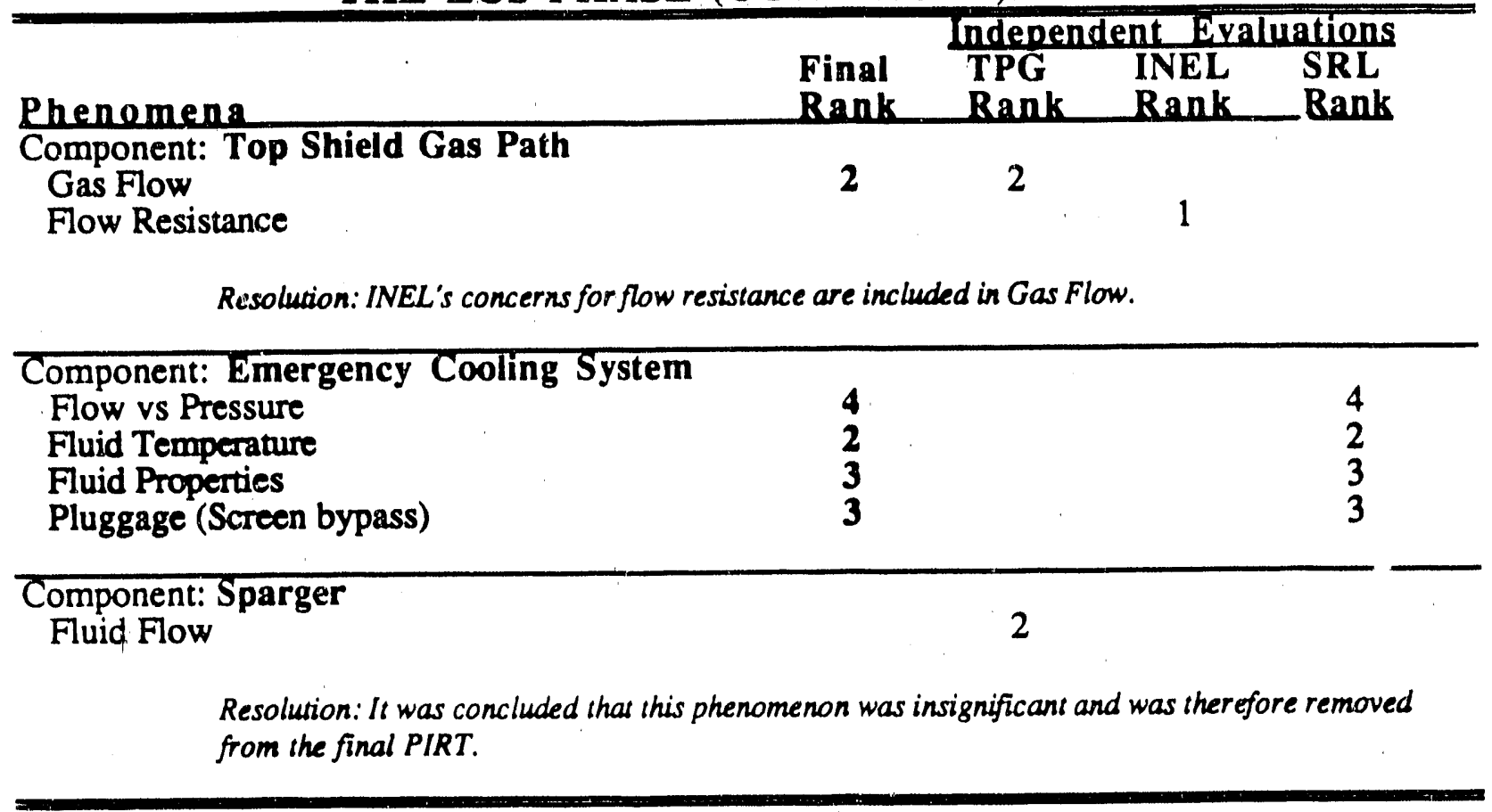



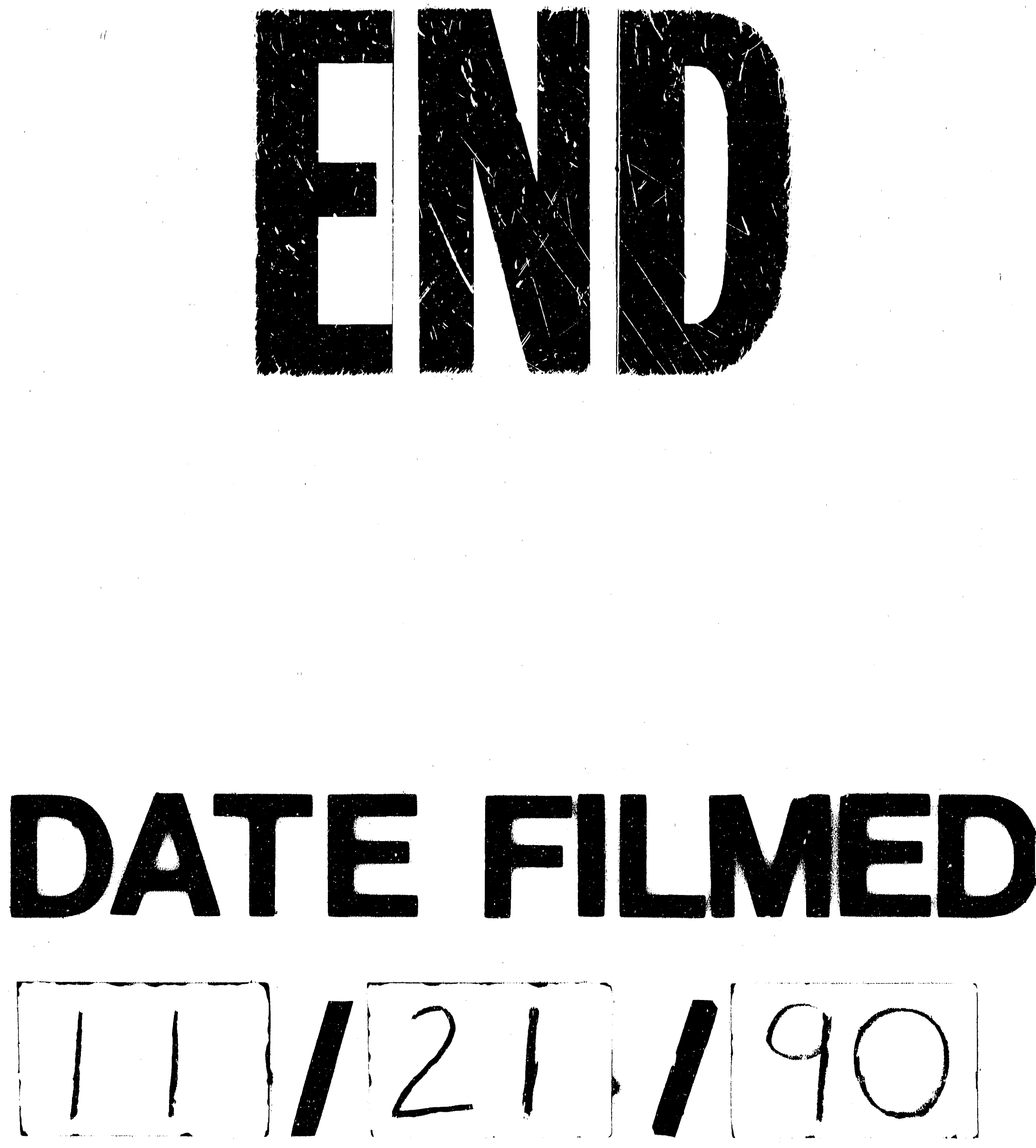
